\title{
Mineral resources in life cycle impact assessment_-defining the path forward
}

\author{
Johannes A. Drielsma ${ }^{1}$ - Andrea J. Russell-Vaccari ${ }^{2} \cdot$ Thomas Drnek $^{3} \cdot$ Tom Brady $^{4}$. \\ Pär Weihed $^{5} \cdot$ Mark Mistry $^{6} \cdot$ Laia Perez Simbor $^{7}$
}

Received: 27 May 2015 / Accepted: 24 October 2015 / Published online: 9 November 2015

(C) The Author(s) 2015. This article is published with open access at Springerlink.com

\begin{abstract}
Purpose Despite 20 years of research, there remains no robust, globally agreed upon method — or even problem statement-for assessing mineral resource inputs in life cycle impact assessment (LCIA). As a result, inclusion of commonly used methods such as abiotic depletion potential (ADP) in life cycle assessment (LCA)-related evaluation schemes could lead to incorrect decisions being made in many applications. In this paper, we explore in detail how to improve the way that life cycle thinking is applied to the acquisition of mineral resources and their metal counterparts.

Methods This paper evaluates the current body of work in LCIA with regard to "depletion potential" of mineral resources. Viewpoints from which models are developed are described and analyzed. The assumptions, data sources, and calculations that underlie currently used methods are
\end{abstract}

Responsible editor: Martin Baitz

Andrea J. Russell-Vaccari

andrea@alignconsultants.com

1 European Association of Mining Industries, Metal Ores and Industrial Minerals, Avenue de Broqueville/Broquevillelaan 12, 1150 Brussels, Belgium

2 Align Consulting, 1134 Cross Creek Ct., Sheridan, WY, USA

3 RHI AG, Magnesitstrasse 30, 8614 Breitenau, Austria

4 Newmont Mining, 6363 South Fiddler's Green Circle Suite 800, Greenwich Village, CO 80111, USA

5 Lulea Technical University, Luleå 971 87, Sweden

6 The Nickel Institute, Avenue des Arts/Kunstlaan, 13, 1210 Brussels, Belgium

7 European Copper Institute, Avenue de Tervueren/Tervurenlaan 168 b-10, 1150 Brussels, Belgium examined. A generic metal-containing product is analyzed to demonstrate the vulnerability of results to the denominator utilized in calculating ADP. The adherence to the concept of the area of protection (AOP) is evaluated for current models. The use of ore grades, prices, and economic availability in LCIA is reviewed.

Results and discussion Results demonstrate that any work on resource depletion in a life cycle context needs to have a very clear objective or LCIA will not accurately characterize mineral resource use from any perspective and decision-making will continue to suffer. New, harmonized terminology is proposed so that LCA practitioners can build better mutual understanding with the mineral industry and recommendations regarding more promising tools for use in life cycle sustainability assessment (LCSA) are given.

Conclusions The economic issue of resource availability should be evaluated in parallel with traditional LCA, not within. LCIA developers should look to economists, the market, and society in general, for broader assessments that consider shorter-time horizons than the traditional LCIA methods. To do so, the concept of the AOP in LCA needs to be redefined for LCSA to ensure that models estimate what is intended. Finally, recommendations regarding mineral resource assessment are provided to ensure that future research has a sound basis and practitioners can incorporate the appropriate tools in their work.

Keywords Abiotic resource depletion - Availability · LCIA . Minerals $\cdot$ Ore grades $\cdot$ Reserves $\cdot$ Resources $\cdot$ Scarcity
Abbreviations
ADP
Abiotic depletion potential
AOP
Area of protection
ASX
Australian Securities Exchange 


$\begin{array}{ll}\text { CAC } & \text { Cumulative availability curve } \\ \text { CF } & \text { Characterization factor } \\ \text { CML } & \begin{array}{l}\text { Centre for Environmental Science, Leiden, } \\ \text { the Netherlands }\end{array} \\ \text { CRIRSCO } & \begin{array}{l}\text { Committee for Mineral Reserves International } \\ \text { Reporting Standards }\end{array} \\ \text { CC } & \text { Crustal content } \\ \text { EPD } & \text { Environmental product declaration } \\ \text { ESP } & \text { Economic scarcity potential } \\ \text { EGR } & \text { Extractable global resource } \\ \text { GNP } & \text { Gross national product } \\ \text { IASB } & \text { International Accounting Standards Board } \\ \text { ICMM } & \text { International Council on Mining and Metals } \\ \text { IIED } & \text { International Institute for Environment and } \\ & \text { Development } \\ \text { ILCD } & \text { International Life Cycle Database } \\ \text { ISO } & \text { International Organization for Standardization } \\ \text { LCA } & \text { Life cycle assessment } \\ \text { LCIA } & \text { Life cycle impact assessment } \\ \text { LCSA } & \text { Life cycle sustainability assessment } \\ \text { LEED } & \text { Leadership in Energy and Environmental } \\ & \text { Design } \\ \text { LME } & \text { London Metal Exchange } \\ \text { MMSD } & \text { Mining, Metals and Sustainable Development } \\ \text { PEF } & \text { Product Environmental Footprint } \\ \text { PGM } & \text { Platinum group metals } \\ \text { REE } & \text { Rare earth element } \\ \text { SETAC } & \text { Society of Environmental Toxicology and } \\ & \text { Chemistry } \\ \text { TSX } & \text { Toronto Stock Exchange } \\ \text { UNEP } & \text { United Nations Environment Program } \\ \text { USA } & \text { United States of America } \\ \text { USGBC } & \text { United States Green Building Council } \\ \text { USGS } & \text { United States Geological Service } \\ \text { WBCSD } & \text { World Business Council on Sustainable } \\ & \text { Development } \\ & \end{array}$

\section{Introduction}

Globally, organizations have been integrating life cycle thinking, tools, and techniques into decision-making for many years. The view of the entire life cycle enables assessment of the environmental impacts associated with all stages of a product or system's life. It also enables the user to uncover tradeoffs across environmental impacts, which could otherwise go unnoticed and are critical to ensuring good decision-making. Life cycle assessment (LCA) has seen a recent resurgence due to its ability to provide this unique view, with green building and government initiatives using LCA results to drive decision-making when comparing products. For example, the United States Green Building Council's (USGBC) Leadership in Energy and Environmental Design (LEED) v4.0 certification protocol provides applicants with points for selecting materials based on life cycle impact assessment (LCIA) results. Additionally, the European Commission's Product Environmental Footprint (PEF) project explores the practicality of setting standards for evaluating products across various environmental LCIA categories. Consequently, this has led to greater focus - and significant debate - on the science behind LCIA methodologies.

While some impact categories are considered robust, many of the commonly used LCIA methodologies are immature and require significant development to ensure that decisionmaking is not driven by highly uncertain, and potentially incorrect, results. Others may simply be inappropriate as a basis for policy-making. This is particularly the case for current methods assessing resource inputs, for which there remains no globally agreed-upon method or even problem statement. Yet, the most commonly used method for abiotic resource depletion (Guinée and Heijungs 1995) is included in many of the schemes that are currently either being utilized or are under development. The risk that this could now lead to incorrect decisions being made in everything from individual product purchases by consumers, high-volume purchasing decisions by large users, regulations across material categories, and investments in new technologies or indeed new supply, is significant. Despite 20 years of research attempting to better estimate resource depletion potential in LCIA, there is still no globally agreed method that is sufficiently robust for such important decision-making.

This paper is organized into several sections. Each section tackles differing views on a critical element of understanding resources, availability, and the concept of depletion. First, the paper explores the mining industry contribution to sustainable development via the landmark Mining, Metals and Sustainable Development (MMSD) project completed at the turn of the twenty-first century. Next, commonly held views of those wishing to better understand mineral resources are summarized. Critical terms used throughout the paper are defined, and a review of how the geological profession estimates different data from crustal content through to mineral reserves is presented. The differences between key terms that are sometimes confused in LCIA are highlighted, and clarity is provided on which should be used to measure what. A detailed look is then taken at why the denominator is so critical when using abiotic depletion potential (ADP) and interpreting life cycle impact assessment results. Next, the importance of prices and traditional economic measures on estimations of mineral availability, as opposed to depletion potential, is reviewed. A closer look at the area of protection concept in LCA and why it has led us away from environmental assessment in the area of mineral resources is provided. It is then demonstrated that any work on resources in a life cycle context needs to have a very clear objective, or results and decision-making will continue to suffer. Finally, new and novel methods for understanding 
the short- and long-term availabilities of mineral resources are presented, along with trusted datasets to aid the practitioner. In conclusion, a set of recommendations are provided, which take the research on this important topic forward into life cycle sustainability assessment (LCSA).

\section{Mining, Metals and Sustainable Development}

Whether concerned about the preservation of ecosystems and landscapes, energy and water use, or the material well-being of future generations, LCA practitioners have been seeking to answer questions about the sustainabilities of mining and mining products for many years. While LCA can help to answer many of the environmental questions about mining, it cannot answer all of the challenges sustainable development presents to the mining industry. At the start of the twenty-first century, a multi-stakeholder, 2-year initiative was completed to help better define how the mining industry contributes to sustainable development (International Institute for Environment and Development (IIED) 2002). Participants in the Mining, Minerals and Sustainable Development (MMSD) project spanned from non-profit organizations with interests in community development and the environment to private industry, governments, and academia from around the world. The World Business Council on Sustainable Development (WBCSD) contracted the not for profit organization, the International Institute for Environment and Development (IIED), to execute the project, which ended up with over 40 sponsors and an assurance group to ensure that project goals were met. The final project report "Breaking New Ground" describes the fine balance required by sustainable development through the management of five types of capital, natural, manufactured, human, social, and financial, and should be an invaluable reference for any LCA practitioner wishing to assess the potential environmental impacts of use of mineral resources.

The report discussed societal concerns about long-run availabilities of resources and environmentalists' calls for a reduction in the material throughputs of modern economies. It called on industry to provide information to ensure that sustainable management of natural resources is sciencebased and emphasized the importance of authoritative, independent, legitimate, accurate, and relevant data. The report referred to the value of continuing to develop LCA as an important management tool for the environmental aspects of sustainable development. Finally, the participants concluded that the potential contribution of minerals to the sustainable development of national economies is far from realized. Many more primary raw minerals will be needed to continue advancing society, for example in new technologies, and a greater contribution from mining can still be made without undue impact on the natural resource.
In its current standardized form (International Organization for Standardization (ISO) 14040 2006), LCA focuses on only a portion of the factors that MMSD stakeholders agreed must be correctly understood and managed. In the context of resources, LCIA approaches have centered mostly on the preservation of natural capital. In recent years, method developers have attempted to incorporate economic and social factors into LCA and LCIA models, with various unsatisfactory results. Most practitioners agree that broader societal questions call for additional linkages to the remaining four forms of capital, which to date have not been successfully established in LCIA. Such links need to extend from LCA to other assessment tools for the full picture to be usefully constructed.

\section{Fixed stock or opportunity cost?}

A significant body of work has been done since the MMSD project to better understand how to evaluate the use of minerals in the context of Sustainable Development. John Tilton, a prominent mineral economist at the Colorado School of Mines, contends in his text, "On borrowed time: assessing the threat of mineral depletion" (2002) and subsequent articles, that the debate over resource depletion includes two mental models. One based on the fixed stock paradigm (i.e., there exists a finite quantity of a given resource or "crustal abundance"), which views resource depletion potential from a pessimistic view of the future. The second being the opportunity cost paradigm, which views resource depletion potential more optimistically as an economic question driven by market demand.

The danger of the fixed stock paradigm lies in the alluringly simple notion that abiotic resources cannot be renewed on a human timescale and therefore could eventually disappear. However, complications arise, because many non-renewable resources (metals, etc.) are indestructible and are regularly renewed from an anthropological standpoint. Metals are not consumed - they can be recycled - and most will go on to have many useful, if not indefinite, lives before eventually being returned to the natural environment. So how does one account for this in the fixed stock view? What is the total stock? How, then, is it depleted? If one decides that the total stock should be the natural occurrence of the resource in the Earth's crust, this is thought of as the planetary boundary and the fixed stock paradigm is applied. If, however, one wishes to define the total stock as the quantity of resource available for human use, the assumed planetary boundary is difficult to detect or justify and the fixed stock paradigm cannot be easily applied.

The opportunity cost paradigm assesses what we have to give up, or pay, in order to have an additional quantity of a given resource. Central to this view is that resource depletion will not be a surprise - if it occurs, we will see it coming many 
years prior in the form of long-term price trends and economic actors will be presented with different choices or opportunities. Economic theory suggests that persistently increasing prices will eventually erode the demand and lower-cost opportunities will be sought, e.g., innovation of alternatives. Basically, we make decisions as humans in our prevailing context of prices in the market. Therefore, using this basic mechanism of price-we control resource availability. For example, if high demand causes the price of lead to raise dramatically, the incentive to discover new deposits and recycle scrap lead increases, as does the incentive to develop technologies which can do the same (or more) with less in consumer goods. We can see examples of this in the cases of copper and zinc, shown in Figs. 1 and 2, where the red line represents price and the blue represents mine production. As demand increases over time, exploration, new technologies, and production ramp up to meet demand and therefore keep long-term average prices in check. Note, however, that shortterm fluctuations in demand (reflected by the prices since 2003) do not affect the rate at which production rates change (later, we will briefly explain why this is so).

Over the last 20 years of work in trying to characterize resource depletion potential, LCIA practitioners have vacillated between the fixed stock and opportunity cost paradigms. This is problematic, because they offer vastly different views of natural resources, which have not always been well understood or communicated in LCIA results. In the fixed stock view, natural resources are to be preserved; it is assumed that use leads to some form of penalty or reduction in value/availability. In the opportunity cost view, natural resources are treated more like flows that need to be managed to best meet human demands. This difference is important. Measuring resource availability to humans requires a different - and much more complex - set of variables than does depletion of natural stocks. We contend that sustainable development requires a true understanding of resource availability. However, by simply trying to adapt the original fixed stock model to questions of availability, LCA practitioners have struggled to adequately address either view.

\section{Definitions matter}

Just as the context in which one approaches the resource depletion issue is critical, so are the language and data we use when models are constructed. One of the most challenging aspects of this field of study in LCIA for the mining industry is that LCA practitioners do not use the traditional definitions utilized by leading geological institutions. Geological surveys such as the United States Geological Service (USGS), stock exchange regulators such as the Australian Securities Exchange (ASX) and Toronto Stock Exchange (TSX), and the International Accounting Standards Board (IASB) are currently converging toward the Committee for Mineral Reserves International Reporting Standards (CRIRSCO) definitions, discussed further below. These reporting standards are recognized and adopted in several countries for market-related reporting and financial investment. The purpose of the CRIRSCO International Reporting Template is to assist with the dissemination and promotion of effective, well-tried, good practice for public reporting of exploration results. The CRIRSCO definitions thus allow reliable and consistent

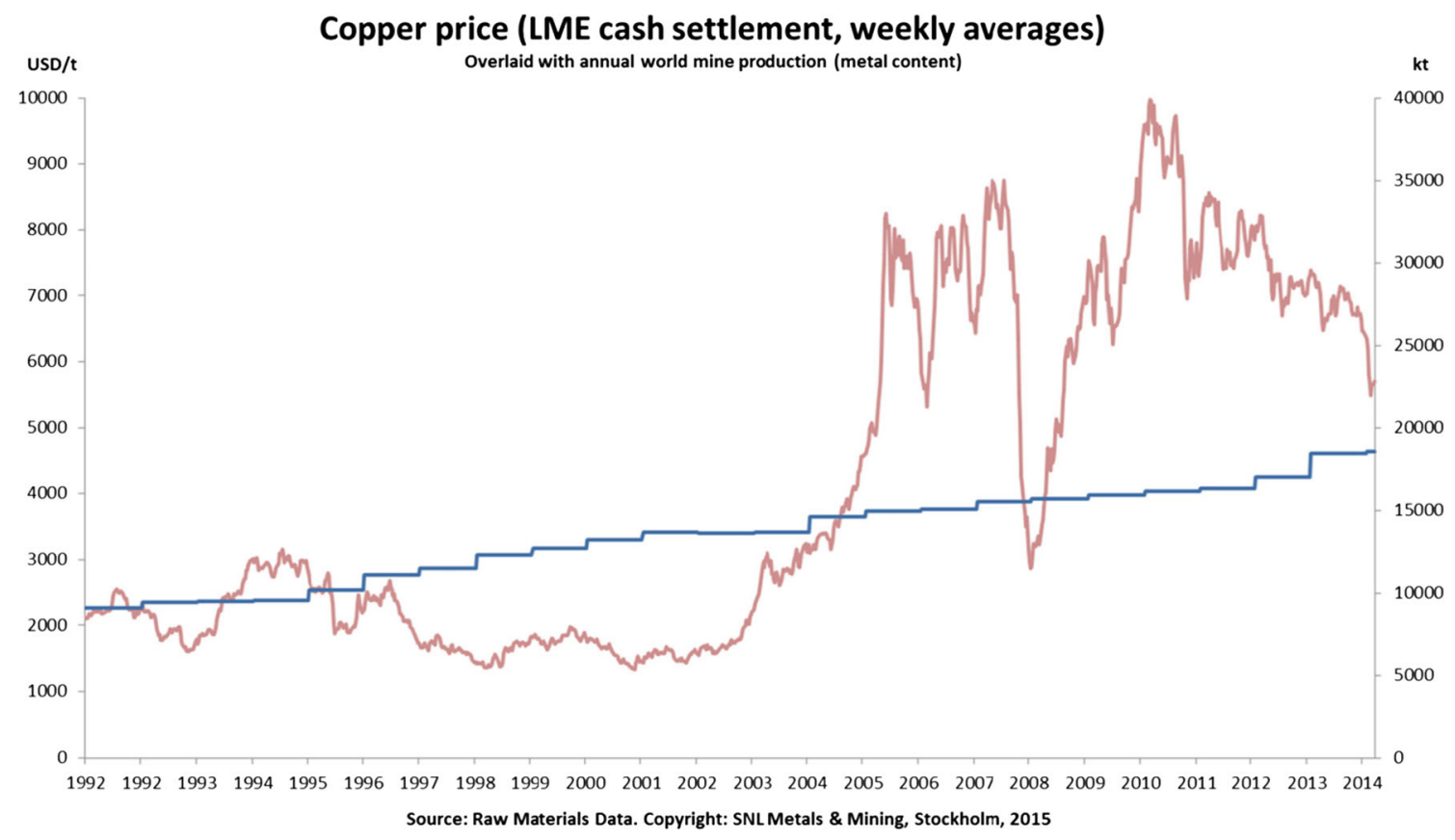

Fig. 1 Copper prices versus production over time. Source: Raw Materials Group (2015) 


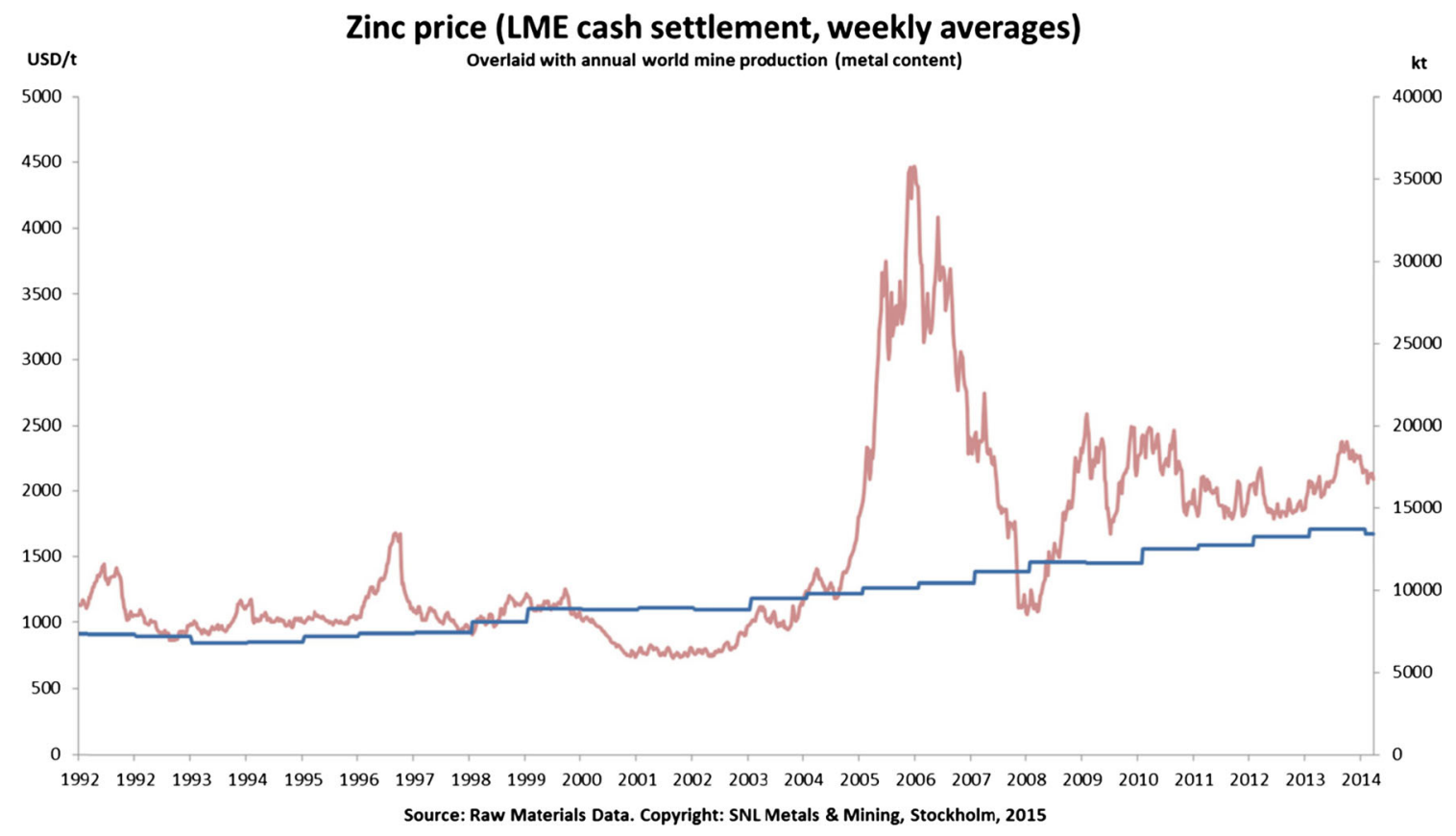

Fig. 2 Zinc prices versus production over time. Source: Raw Materials Group (2015)

interpretation of data and comparison across jurisdictions. The definitions of resources and reserves in a Western context (i.e., for publically listed companies) have an economic overlay. In other non-Western jurisdictions (e.g., former Soviet Union and China), the resource classifications are more in line with a "total occurrence" type classification that does not necessary imply that the material can be extracted at a profit. Use of the CRIRSCO template helps to clearly distinguish the two types of data and avoid misinterpretation and costly errors. Whereas CRIRSCO definitions are widely used to govern the way in which private sector mineral assets are reported to stakeholders, CRIRSCO does not itself require reporting nor does it provide any global statistics. USGS definitions of mineral resources and reserves are very similar to the CRIRSCO definitions, but they serve different purposes and, in practice, allow for a range of assumptions about prevailing prices. If LCA is to be understood and supported by mining companies and their stakeholders, the CRIRSCO definitions of terms should be adopted. This section presents our terms and definitions drawing on industry practice and compares them to terms used in current LCIA practice.

Crustal content represents the total amount of an element in a given layer of the Earth's crust. It is also referred to as "crustal abundance" in the literature and is estimated by multiplying the average concentrations of chemical elements in the crustal layer by the mass of the same crustal layer. Crustal content is a fixed parameter that can be readily associated with the commodity under consideration. This concept allows comparative characterization of resources with respect to depletion potential, but the crustal content of an element will never be extracted completely as some deposits/concentrations will remain unavailable under all foreseeable economic conditions (i.e., no one will want to pay the price to access them). This definition matches that of Guinée and Heijungs (1995) and Annema et al. (1993) to describe what they called the "ultimate reserve." However, the use of the term "reserve" to describe crustal content is misleading because, if using mining industry terminology, it implies that the whole quantity is currently economically available - which is far from being the case.

Extractable global resource is the amount of crustal content that will ultimately prove extractable by humans. This definition matches that of Guinée and Heijungs (1995) to describe what they called the "ultimately extractable reserve." In theory, it is a fixed quantity. As will be discussed further below, Graedel et al. (2011) have studied this closely for several minerals and were unable to develop reliable estimates. Tilton (2001) maintains that it is likely an unknowable quantity, due to constantly changing variables and the unpredictability of humans' ability to adapt to constraints in the market. Again, Guinée and Heijungs' (1995) use of the term reserve is problematic here because we are talking about a "resource" as defined by CRIRSCO.

Mineral resource (Committee for Mineral Reserves International Reporting Standards (CRIRSCO) 2013) "is a concentration or occurrence of solid material of economic interest in or on the Earth's crust in such form, grade or quality, and quantity that there are reasonable prospects for eventual economic extraction. The location, quantity, grade or quality, continuity, and other geological characteristics of a mineral resource are known, estimated, or interpreted from specific geological evidence and knowledge, including sampling." 
Resources are dynamic - their size increases and decreases based on a number of factors, as explored in more detail in Sect. 5 below. This definition matches that of van Oers et al. (2002) to describe what they call the reserve base. This poses at least two problems for current LCA practice: first, it overlaps with the CRIRSCO definition of resource and therefore confuses the concept of resource with reserves, of which the latter are a subset of the former; second, it does not match the definition of reserve base adopted by the USGS, which is the data source most commonly used in LCA. Until 2010, the USGS published "reserve base" data that was actually a subset of total resources (see Crowson (2011a) for a full discussion of the limitations of USGS Mineral Commodity Summary statistics).

Mineral reserve (CRIRSCO 2013) "is the economically mineable part of a measured and/or indicated mineral resource. It includes diluting materials and allowances for losses, which may occur when the material is mined or extracted and is defined by studies at pre-feasibility or feasibility level as appropriate that include application of modifying factors. Such studies demonstrate that, at the time of reporting, extraction could reasonably be justified." Just like resources, reserves are dynamic - their size increases and decreases based on a number of factors, explored in more detail in Sect. 5 below. This definition matches that of van Oers et al. (2002) to describe what they called the economic reserve. However, their use of the term reserve is redundant because according to CRIRSCO, all reserves are economically viable.

Resource depletion is the process of physically reducing the global amount of a specific resource. It refers to the reduction of geological/natural stocks over time - not of an individual mine or ore body (adapted from van der Voet 2013 and Merriam-Webster 2015). Resource depletion can also refer to the end point of the process (i.e., complete exhaustion of the global resource) (Mancini et al. 2013; Tilton 2002). At times, stakeholders in the mining industry may speak about reserve depletion, which is different again; reserve depletion describes the mining out of already identified mineral reserves and the challenges that may present for individual mining operations, their host communities, or indeed whole nations. van Oers et al. (2002) define resource depletion as "the decrease of availability of the total reserve of potential functions of resources" and imply that resource depletion relates to reduced availability in the long term.

Resource availability is an economic term that refers to the accessibility, presence, or readiness of a resource for human use (adapted from Merriam-Webster 2015). A resource may have relatively high resource depletion potential and at the same time be highly available economically (e.g., mercury). Conversely, a resource may have very low resource depletion potential but at the same time be less available (e.g., phosphate). Although USGS estimates indicate that resources of phosphate rock are abundant, the European Commission has classified phosphate rock as a "critical raw material" because of perceived supply risks in the period 2014-2024 (European Commission 2014).

The most critical point of confusion in the terminology utilized currently in LCIA methods is the persistent use of the term reserve. In the mining industry, anything that is referred to as a reserve has a high level of feasibility and is economic to extract in the current or short-term future. The CRIRSCO standard would class the reserve base of Guinée and Heijungs (1995) as mineral resources and economic reserves as mineral reserves. This fundamental difference in terminology is critical to ensuring that the two disciplines understand each other, not only in the development of new methodologies and use of data but in everyday discussions.

\section{From crustal content to mineral reserves}

CRIRSCO has described the process of converting resources into reserves in Fig. 3. Essentially, this process requires a positive evaluation of many modifying factors, including mining, metallurgical, economic, marketing, legal, environmental, infrastructure, social, and governmental considerations (CRIRSCO 2013). As the double-headed arrows in the center of the figure indicate, this is not a one-way process and the modifying factors regularly cause setbacks to mining projects as reserves are "lost" to re-classification as resources. Still, there are new discoveries, as mining companies collectively do not stop exploring entirely. A recent example of this is the Laver deposit in Sweden, announced in 2012 as a 500-700 $\times$ $10^{6} \mathrm{t}$ mineralization containing copper, gold, silver, and molybdenum that was classified as an "exploration result," before further investigation could later confirm it contained $690 \times 10^{6}$ t of mineral resource (Boliden 2012).

Political regimes can also significantly affect access to mineral resources as can technological advances. Mountain Pass

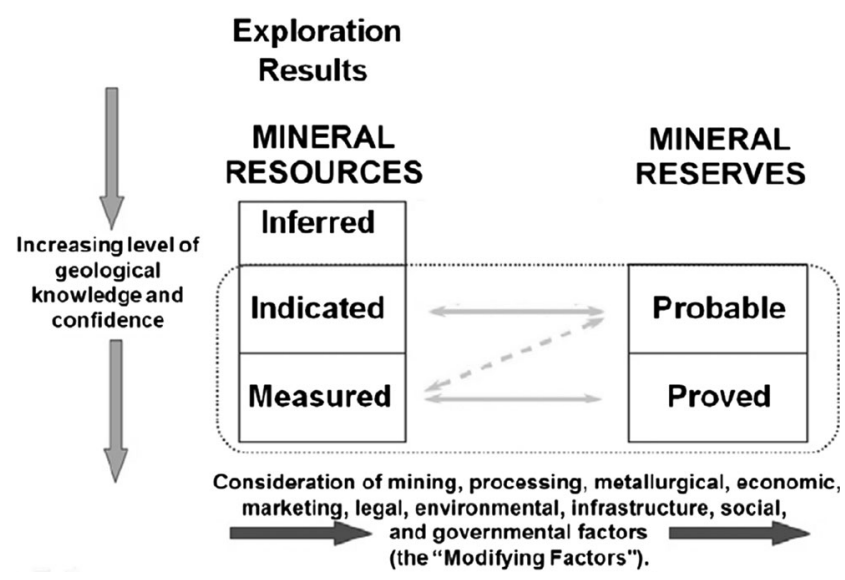

Fig. 3 General relationship between exploration results, mineral resources, and mineral reserves. Source: CRIRSCO (2013) 
rare earth element (REE) mine in Southern California is an example of political, economic, and technical factors at work. In 2002, mining was suspended due to a lack of demand for REE and various environmental challenges. China had brought several new sources of rare earth elements onto the market, lowering prices, and so active mining was stopped. In the late 2000s, China began limiting its exports of REE and the US government - as well as many others - became concerned, due to continued demand from the defense and electronic industries. In 2010, the House Committee on Science and Technology created a bill to help subsidize US sources of REE, stimulating domestic production (Ostin 2013). Although this bill was never brought into law, over 200 new mining projects were being evaluated between early 2010 and mid-2011. Investors bought the Mountain Pass deposit and site in 2008, and in October 2011, they found an additional deposit that contains terbium, yttrium, and dysprosium nearby (Gee 2014). It is useful to note that rare earth elements are not actually rare - they are some of the most commonly found elements in the Earth's crust-however, they are difficult to separate and process.

This adjustment and re-adjustment to changes in demand affect not only the mineral reserves and mineral resources but also exploration, investment, production, recycling, new technologies, etc. The role of exploration is crucial to the process as - provided that there is continued demand for the material-it typically compensates for extraction of reserves through the identification of new resources, which are then converted to reserves with further study (Tilton 2001).

So how does this relate to crustal content? In Fig. 4, we depict the crustal content as the assumed "fixed stock" of any element and show its translation into resources and reserves. The dotted lines of the arrow indicate that resources and reserves are never "fixed"- new resources are found, just as resources become reserves, and may transfer back to being resources as factors fluctuate over time and geological knowledge improves. Thus, any reporting of the respective proportions of resources and reserves within the crustal content is a snapshot mapping of current understanding of available data - and most notably, on the basis of foreseeable market demand, prices, and production costs (see also Herrington 2013). The mining industry does not report figures for crustal content, although reliable listings of average concentration (Clarke values) do exist, such as Rudnick and Gao (2003).

\section{Mineral resources measure economic availability, not physical depletion}

While crustal content estimates have not changed significantly over time, mineral resource and reserve data are subject to significant variation over time for a variety of reasons. This makes it unsuitable for use in LCIA. The next two sections will explore this assertion and the potential ramifications on LCIA results and consequently decision-makers.

As noted above, the ADP method was initially published in 1995 by Jeroen Guinée as part of his PhD thesis at the Centre for Environmental Science (CML) at Leiden in the Netherlands (Guinée 1995) and further defined the same year in an article published by Guinée and Heijungs in Environmental Toxicology and Chemistry (1995). It is a mass-based, dimensionless, characterization factor derived by dividing the annual production (de-accumulation) of a given raw material by the squared crustal content. This result is then multiplied by the life cycle inventory result (extraction) for each abiotic resource included in the study, to produce an effect score or "potential." As described in van Oers et al. (2002), ADP is typically calculated as follows (adapted using the mining industry terminology presented above):

abiotic depletion $=\sum_{i} \mathrm{ADP}_{i} \times m_{i}$

with

$\mathrm{ADP}_{i}=\frac{D R_{i} /\left(R_{i}\right)^{2}}{D R_{\mathrm{ref}} /\left(R_{\mathrm{ref}}\right)^{2}}$

and

$\mathrm{ADP}_{i} \quad$ Abiotic depletion potential of resource (dimensionless);

$m_{i} \quad$ Quantity of resource $i$ extracted $(\mathrm{kg})$;

$R_{i} \quad$ Assumed stock (crustal content/reserve base/mineral reserves) of resource $(\mathrm{kg})$;

$D R_{i} \quad$ Extraction rate of resource $\left(\mathrm{kg} \cdot\right.$ year $\left.^{-1}\right)$;

$R_{\text {ref }} \quad$ Assumed stock of the reference resource, antimony $(\mathrm{kg})$;

$D R_{\text {ref }}$ Extraction rate of the reference resource, $R_{\text {ref }}\left(\mathrm{kg} \cdot\right.$ year $\left.^{-1}\right)$.

ADP can also be calculated without the extraction rate as described in van Oers et al., where it is recommended as "alternative 2 " (2002) as follows:

$\operatorname{ADP}_{i=\frac{1}{\left(R_{i}\right)}}$

Because of the nature of the equation, the result is highly sensitive to the size of the assumed stock and therefore variability in that stock over time. This has led many to debate which denominator (crustal content, reserve base, or mineral reserves) best represents the AOP natural resources (see Guinée and Heijungs 1995; van Oers et al. 2002; European Commission Joint Research Centre (EC-JRC) 2011; Klinglmair et al. 2013; Schneider et al. 2013). Guinée and Heijungs (1995) and Tilton (2002) agree that there are "two ways to measure depletion: depletion measured by economic 
Fig. 4 Depiction of the relationship between crustal content, resources, reserves, and the technosphere

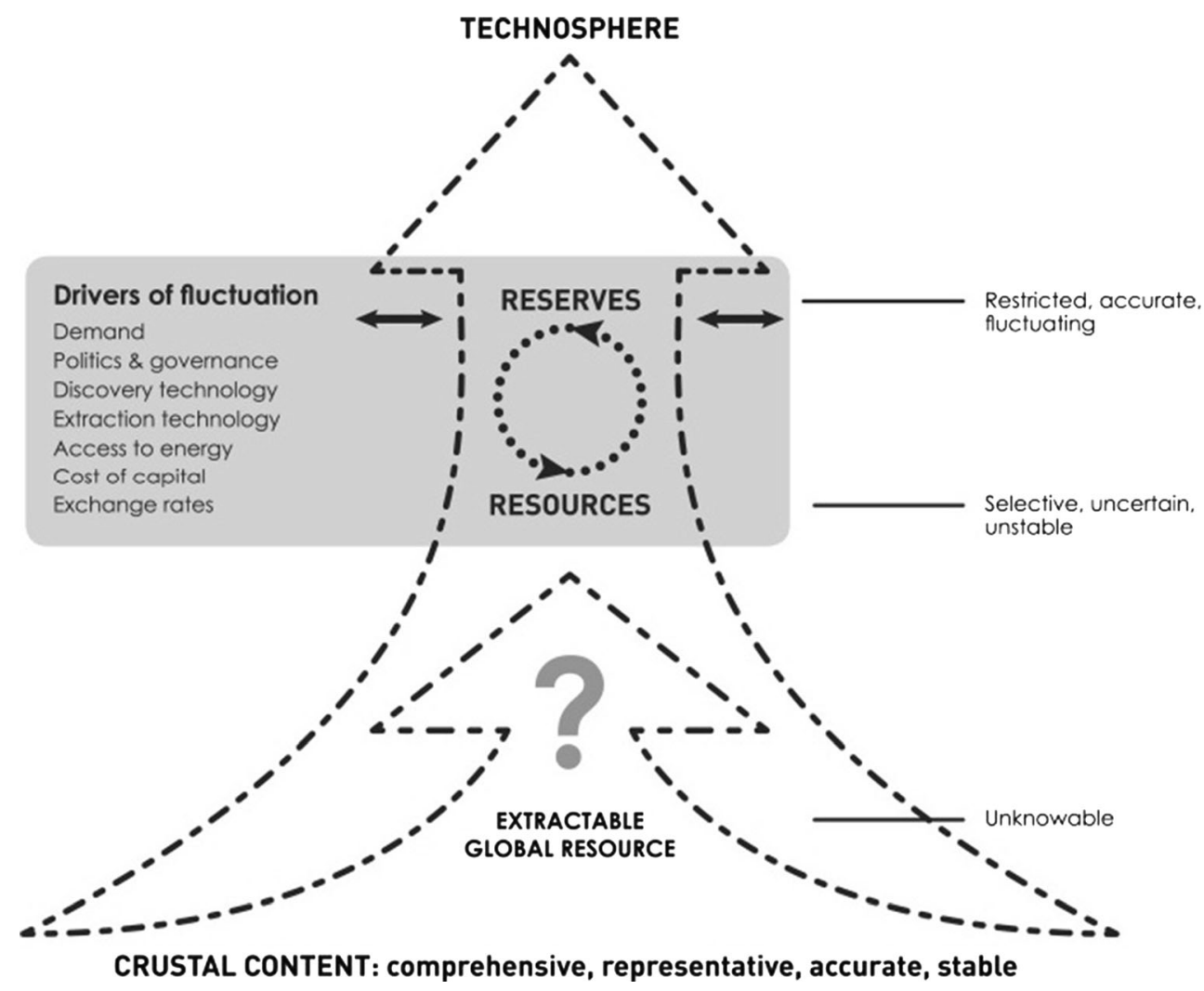

data (price) versus depletion measured by physical data (reserves, de-accumulation, and entropy)." First, we will examine in more detail the impact of using the economic data (reserve base-USGS estimate of a subset of mineral resources) currently recommended by the International Life Cycle Database (ILCD) Handbook (EC-JRC 2011) and required by the European Commission's PEF pilot project (European Union 2013) in the denominator.

Figures 5, 6, and 7 for iron ore, copper, and indium show that the economic data (mineral reserves and mineral resources) change annually in response to demand, exploration and supply cycles, politics, and socioeconomic trends. The reserve base data is incomplete, as it is no longer reported by the USGS. Finally, included in the charts for comparative purposes is what the USGS refers to as "world resources," corresponding to mineral resources as defined by CRIRSCO above.

Figure 5 shows that the iron ore reserve base has fluctuated over recent years - together with market demand - as a result of frequent reviews of the estimate. Meanwhile, the USGS estimate of total world resources has remained unchanged (exploration has concentrated on conversion of known resources into reserves).

Figure 6 demonstrates that copper reserve base has continually increased over the same period as a result of frequent reviews of the estimate. This reflects the general tendency for
Fig. 5 Comparison of USGS reported data for iron ore

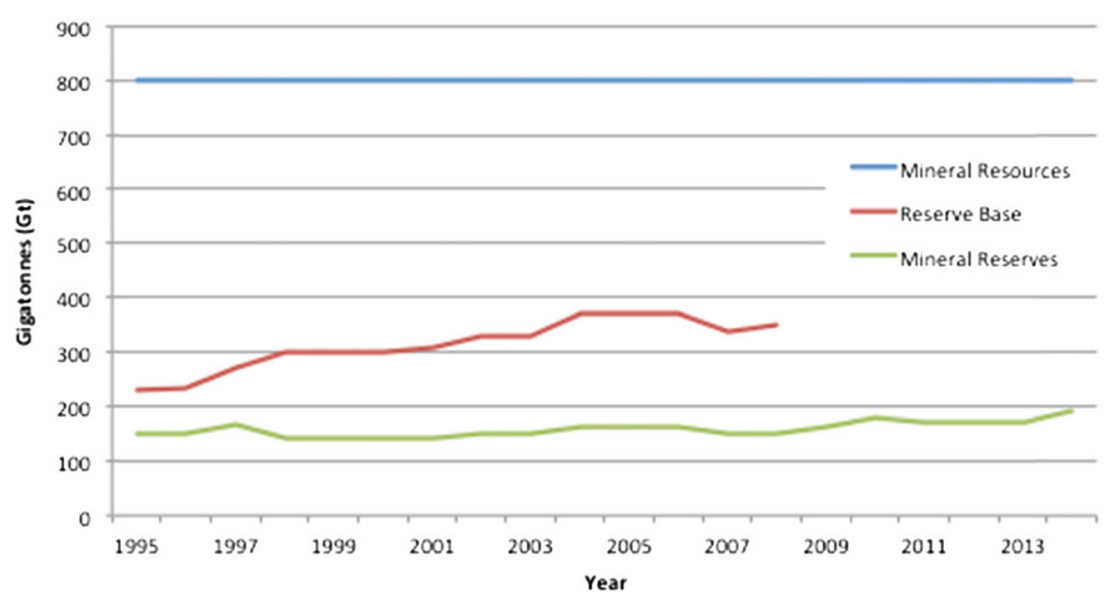


Fig. 6 Comparison of USGS reported data for copper

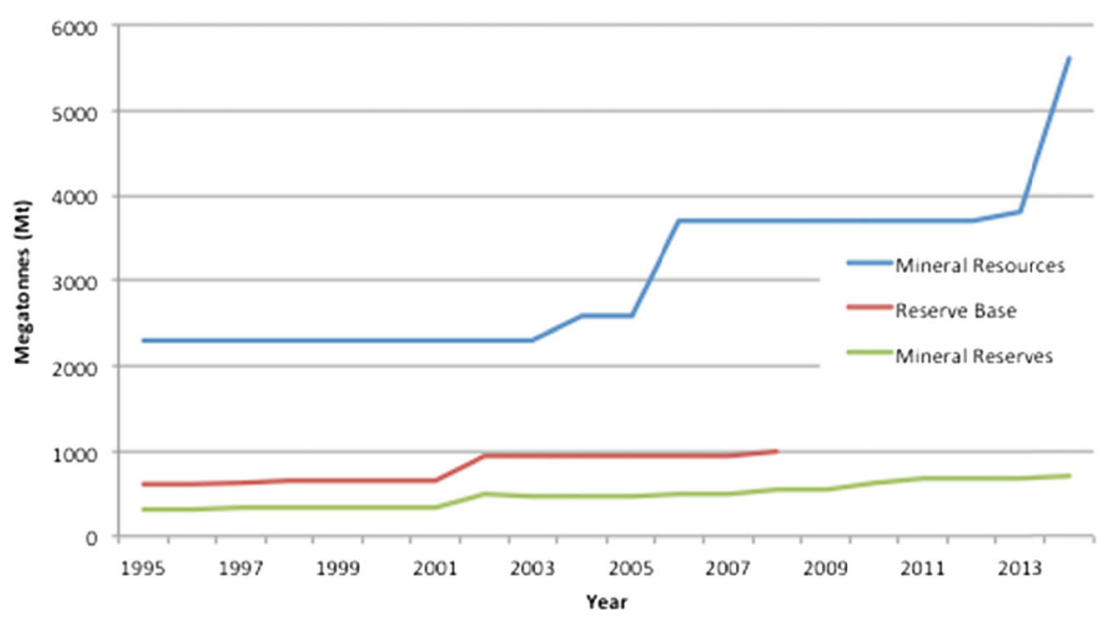

higher demand to stimulate higher exploration expenditure. In the early $1970 \mathrm{~s}$, copper resources were estimated at $1.6 \times 10^{9} \mathrm{t}$ by the USGS (Erickson 1973). This estimate was then updated to $3.7 \times 10^{9} \mathrm{t}$ in 2006 and is now estimated at $5.6 \times 10^{9} \mathrm{t}$ (Johnson et al. 2014; Tilton and Lagos 2007). These are significant changes - 3.5 times what we once believed to be available or exploitable.

Figure 7 shows that the indium reserve base has consistently been underreported and the USGS stopped reporting it after 2007 (the last estimate was dominated by reserves in China). Additionally, the USGS has not published any estimate of total world indium resources. Indium is a by-product of zinc mining, and the consistent underestimation of its resources and reserves reflects the fact that there is no active exploration for indium, because by-product indium fully satisfies demand.

According to the USGS, in addition to the variables outlined above, changes in its estimates can also be a result of any of the following: (1) changes in specialists assigned to commodities and their subjective rationale for inclusion in different categories; (2) more publishing and standardization of data to comply with legal reporting requirements; (3) better distribution of data through purchased studies and access to databases; and (4) cooperative agreements and increased contacts with governments, international study groups, and industry (Bleiwas D, personal communication, 2015). USGS reserve estimates cannot therefore be relied upon to answer the resource depletion question in the same way for all commodities. USGS data are intended to inform about each individual commodity's market conditions and can only be correctly interpreted together with the qualitative information provided in USGS commodity summaries.

Graedel et al. (2011) have attempted to remedy the problem of ever fluctuating reserve and resource data by trying to calculate what they call the extractable global resource, as defined above. The extractable global resource (EGR) is expressed as a probability distribution, with upper and lower limits. Estimating upper limits becomes very challenging because the authors make it clear that EGR will change over time as demand and technology develop. This makes it very difficult and highly speculative, for example, to determine whether what is now a by-product will ever be economically mined as a main product. Finally, they conclude that it is not possible to reliably estimate EGR for any metal.

Schneider et al. (2015) also attempt to calculate EGR. The authors calculate three different options, each with different percentages of the crust assumed to be ultimately available.
Fig. 7 Comparison of USGS reported data for indium

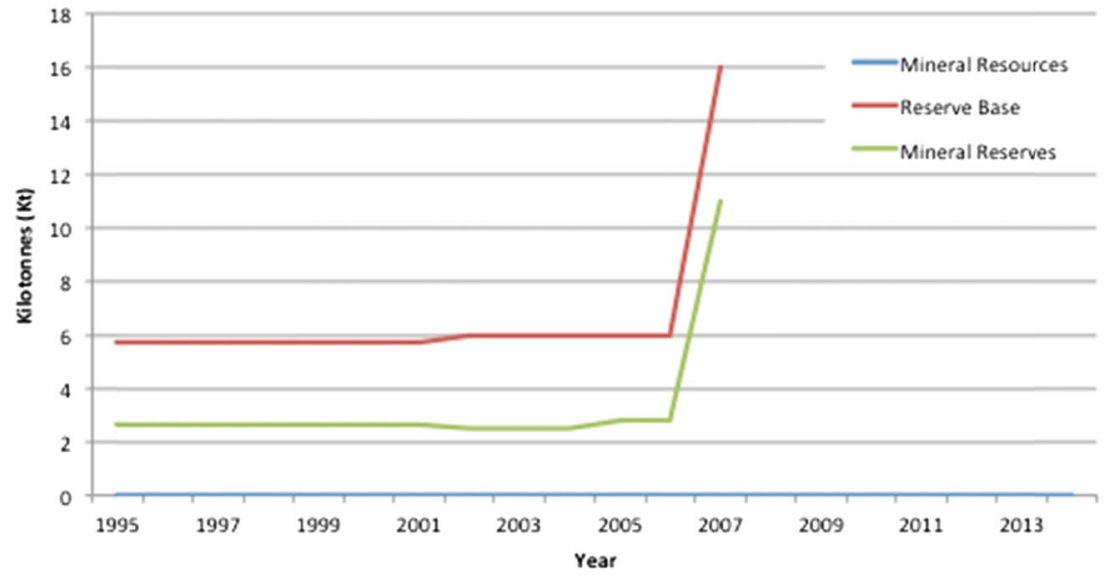


The difficulty with this approach is exemplified by Graedel et al. (2011). The relationships between carrier and co-metals are extremely complex and differ not only by ore type but also by host rock. Using a single assumption, or even two assumptions, to define minimum mineable grades for all metals is a generalization that will not lead to a more certain estimate of EGR. Certainly, it produces what might seem to be a more logical number, because it is smaller than crustal content and larger than resources, but its basis is so uncertain that its use is not likely helpful for improving the calculation of ADP.

Kesler's work in developing ore genesis models (Kesler and Wilkinson 2008) is likely the most correct path forward in attempting to determine plausible EGR for a given mineral. Such work has only been completed for a handful of ore types to date and would be needed for every ore type of a broad spread of metals and minerals before it could be relied upon as a baseline for LCIA. As Graedel et al. (2011) point out that, and is noted above, meaningful estimates of EGR are not possible at this time by geological experts most knowledgeable in the field. Thus, they are not possible for generalists developing an LCIA model.

\section{What is in the denominator matters for decision-makers using LCA}

As discussed above, the impact of changing reserve data on characterization factors (CFs) is significant and can influence the outcome of decision-making in comparative LCA. Table 1 highlights this problem, with the "percent change" column providing a comparison of the changes in characterization factors for various minerals versus the previous year (1999 vs 1992 and 2009 vs 2009). These years were selected for comparison because 1992 and 1999 were the datasets used in Guinée and Heijungs (1995) and van Oers et al. (2002). Also, 2009 was the final year the USGS published reserve base estimates, as noted above. As is shown, depending on the choice of reserve base or mineral reserve and year, there can be order of magnitude changes in the $\mathrm{CF}$ for a given mineral.

What effect does this have on decision-making? Take the example of a comparative LCA of fictional product from which we are trying to derive a policy or product design decision. Assume we have two product design selections we can make, with the bill of materials shown in Table 2.

If we evaluate the ADP results for each product including the van Oers et al. (2002) baseline approach (crustal content including extraction rate) and alternative 2 (crustal content only or $1 /$ reserve), we can see how the results become even more confusing in Fig. 8. Not only do the results fluctuate significantly - if we use crustal content, a different product selection will be made. Further, when using an economic measure of resources, such as reserve base or mineral reserves, indiumthe most uncertain of the data included in this analysis - dominates the analysis and drives the interpreter to select product $\mathrm{B}$. Also note how significantly the total ADP reduces by updating to the economic data from 2009. Figure 8 essentially shows the effects of both the denominator and time on the decision analysis when using economic data to determine depletion potential of a product. Figure 9 then removes the 1992 and 1999 data to enable a more detailed analysis of the baseline method versus the updated reserve base or alternative 1. See Table 3 for the data supporting Fig. 9.

Thus, not only is the resulting decision reversed but the crustal content methods are dominated by platinum, as opposed to indium. This is a result of platinum having a lower crustal content than indium. In other words, platinum is more rare in the environment than indium. This is key — because, as noted above, indium is a by-product; is not explored for; and as such, its mineral reserves have historically been underestimated. Therefore, LCIA methods that use these as their basis will exaggerate the impact of using indium and lead to an incorrect result - whether considering long-term environmental impact on the natural resource or even long-term access by future generations to that natural resource.

\section{The fixed stock approach: calculating crustal content}

It has often been stated that the depletion problem can never be completely verified empirically (Guinee and Heijungs 1995). While this argument seems logical, in fact, crustal contents

Table 1 Characterization factors by denominator and year for select metals

\begin{tabular}{|c|c|c|c|c|c|c|c|c|c|c|}
\hline \multirow{3}{*}{$\frac{\text { Mineral }}{\text { Copper }}$} & \multicolumn{5}{|c|}{ Reserve base } & \multicolumn{5}{|c|}{ Mineral reserves } \\
\hline & \multirow{2}{*}{$\frac{1992}{9.32 \mathrm{E}-03}$} & \multicolumn{2}{|c|}{$199+$ percent change } & \multicolumn{2}{|c|}{2009 percent change } & \multirow{2}{*}{$\frac{1992}{2.70 \mathrm{E}-02}$} & \multicolumn{2}{|c|}{1999 percent change } & \multicolumn{2}{|c|}{2009 percent change } \\
\hline & & $2.50 \mathrm{E}-03$ & $-73 \%$ & $1.90 \mathrm{E}-03$ & $-24 \%$ & & $3.94 \mathrm{E}-03$ & $-85 \%$ & $1.50 \mathrm{E}-03$ & $-62 \%$ \\
\hline Indium & $2.41 \mathrm{E}+03$ & $5.55 \mathrm{E}+03$ & $-77 \%$ & $2.54 \mathrm{E}+02$ & $-54 \%$ & $7.70 \mathrm{E}+03$ & $1.15 \mathrm{E}+03$ & $-85 \%$ & $1.28 \mathrm{E}+02$ & $-89 \%$ \\
\hline Platinum & $1.64 \mathrm{E}+01$ & $9.09 \mathrm{E}+00$ & $-45 \%$ & $1.35 \mathrm{E}+01$ & $48 \%$ & $1.82 \mathrm{E}+01$ & $4.85+00$ & $-73 \%$ & $4.09 \mathrm{E}+00$ & $-16 \%$ \\
\hline Nickel & $2.76 \mathrm{E}-02$ & $4.18 \mathrm{E}-03$ & $-85 \%$ & $7.42 \mathrm{E}-03$ & $78 \%$ & $1.21 \mathrm{E}-01$ & $1.69 \mathrm{E}-02$ & $-86 \%$ & $8.13 \mathrm{E}-03$ & $-52 \%$ \\
\hline Iron & $1.33 \mathrm{E}-05$ & $1.66 \mathrm{E}-06$ & $-88 \%$ & $5.11 \mathrm{E}-06$ & $208 \%$ & $2.52 \mathrm{E}-05$ & $3.64 \mathrm{E}-06$ & $-86 \%$ & $5.86 \mathrm{E}-06$ & $61 \%$ \\
\hline
\end{tabular}


Table 2 Bill of materials for products A and B

\begin{tabular}{lll}
\hline Mineral & Product A $(\mathrm{kg})$ & Product B $(\mathrm{kg})$ \\
\hline Copper & 1 & 0.5 \\
Indium & 0.05 & 0.02 \\
Platinum & 0.01 & 0.03 \\
Nickel & 0.25 & 0.4 \\
Iron & 4 & 3 \\
\hline
\end{tabular}

have been calculated, confirmed, and refined based on decades of field measurements. One of the most commonly used estimates of the total stock of resources was published in 1924, by Clarke and Washington. They based their estimate on hundreds of samples of exposed rocks at the surface. Utilizing the data gathered, they calculated the average composition of the lithosphere to a depth of 10 miles (the upper crust).

Since then, many studies have sought to verify these numbers. Rudnick and Gao (2003) provide a robust comparison of several studies done over the 90 years and provide updated figures based on these. Table 4 contains data excerpted from their publication Composition of the Continental Crust for major elements. It is clear by comparing these data element by element that the estimates have not changed significantly over the 90-year time span (data for trace elements can be found in Table 11, p. 53, of the same publication).

Thus, while the entire resource has not been directly measured, there is high confidence in its characterization as a result of multiple sampling exercises and calculation methods (Fleischer and Parker 1967; Rudnick and Gao 2003). Crustal content is a stable, comprehensive dataset, with which a physical estimate of resource depletion for abiotic resources-if desired and/or useful — could be estimated.

\section{The opportunity cost approach: prices and availability}

Renewed interest in resource availability is partly due to the high and volatile commodity prices experienced since around 2003. As can be seen in the definitions above, mineral resources are partly defined by what can be "economically extracted" and mineral reserves by what is "economically mineable" at the time of reporting. This is complicated by the time dimension. Qualified experts take a longer-term view of likely profit margins when deciding what can be reported as a mineral resource, whereas reported mineral reserves are directly affected by companies' immediate decision-making. The volatility of raw material prices certainly makes mineral reserve data unreliable for use in calculating resource depletion potential as it has been defined in LCA to date.

Economic theory tells us that price measures the availability of the good on the market. Figure 10 illustrates how price changes with demand in economic cycles. Because short-term demand for metal-containing products is strongly influenced by changes in income, short-term demand tends to coincide with cycles in gross national product (GNP) - represented by the red line. At the time of a boom or upturn, investments are made, production capacity is called upon, disposable incomes increase, and metal demand is higher, whereas during times of recession or depression, investments dry up, much less production capacity is used, disposable incomes decrease, and metal demand is lower. The distance between the red line and the capacity of production provides a measure of the availability of the metal on the market. Market demand and perceptions of this short-term availability determine metal prices and directly affect reported mineral reserves. Other mineral product prices are less cyclical, but they are similarly
Fig. 8 Comparison of products by ADP method

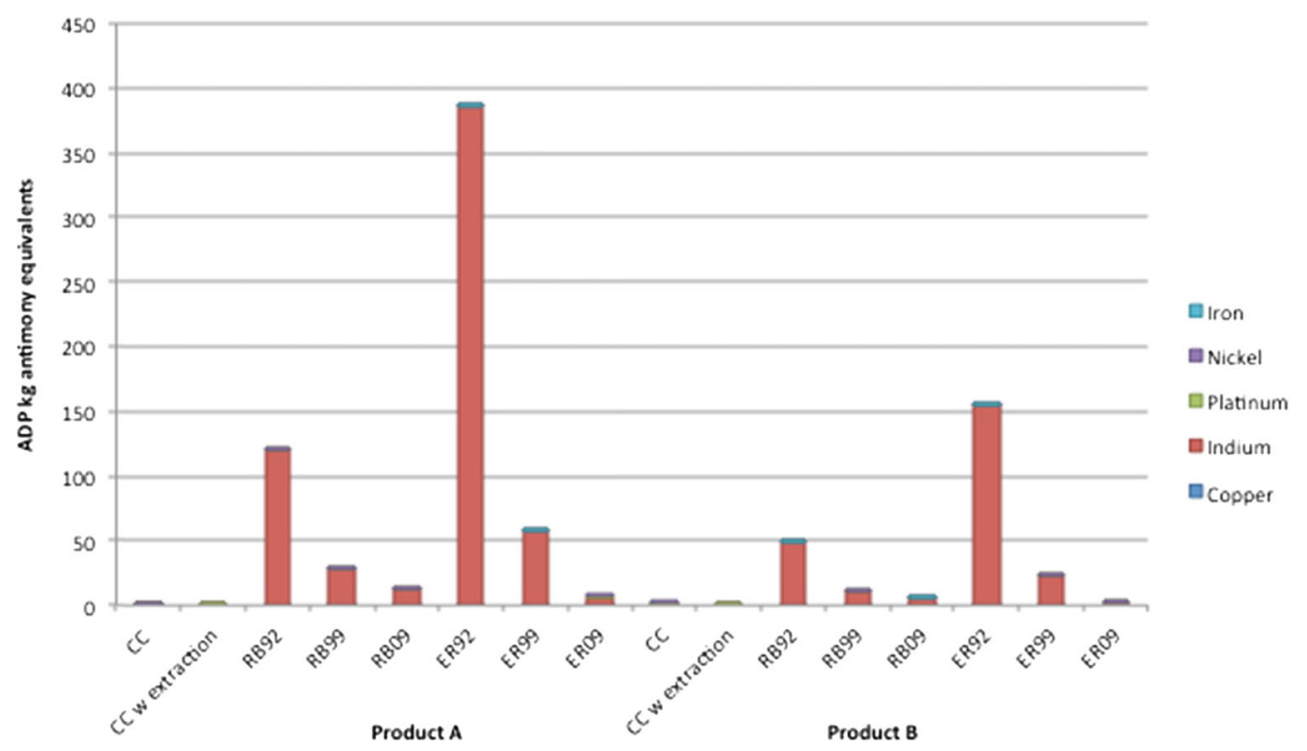


Table 3 ADP results for products A and B by method, 2009 onward

\begin{tabular}{|c|c|c|c|c|c|c|c|c|c|c|}
\hline \multirow[b]{2}{*}{ Mineral } & \multirow[b]{2}{*}{ Product A (kg) } & \multirow[b]{2}{*}{ Product B (kg) } & \multicolumn{4}{|l|}{ Product A } & \multicolumn{4}{|l|}{ Product B } \\
\hline & & & $\mathrm{CC}$ & $\mathrm{CC}$ w extr & ct RB09 & ER09 & $\mathrm{CC}$ & $\mathrm{CC}$ w extract & RB09 & ER09 \\
\hline Copper & 1 & 0.5 & $3.64 \mathrm{E}-03$ & $1.36 \mathrm{E}-03$ & $1.90 \mathrm{E}-03$ & $1.50 \mathrm{E}-03$ & $1.82 \mathrm{E}-03$ & $6.82 \mathrm{E}-04$ & $9.48 \mathrm{E}-04$ & $7.48 \mathrm{E}-04$ \\
\hline Indium & 0.05 & 0.02 & $9.90 \mathrm{E}-02$ & $6.90 \mathrm{E}-04$ & $1.27 \mathrm{E}+01$ & $6.42 \mathrm{E}+00$ & $3.96 \mathrm{E}-02$ & $2.76 \mathrm{E}-04$ & $5.09 \mathrm{E}+00$ & $2.57 \mathrm{E}+00$ \\
\hline Platinum & 0.01 & 0.03 & $4.00 \mathrm{E}-01$ & $1.86 \mathrm{E}-02$ & $1.35 \mathrm{E}-01$ & $4.09 \mathrm{E}-02$ & $1.20 \mathrm{E}+00$ & $5.58 \mathrm{E}-02$ & $4.05 \mathrm{E}-01$ & $1.23 \mathrm{E}-01$ \\
\hline Nickel & 0.25 & 0.4 & $6.68 \mathrm{E}-04$ & $1.60 \mathrm{E}-05$ & $1.86 \mathrm{E}-03$ & $2.03 \mathrm{E}-03$ & $1.07 \mathrm{E}-03$ & $2.56 \mathrm{E}-05$ & $2.97 \mathrm{E}-03$ & $3.25 \mathrm{E}-03$ \\
\hline Iron & 4 & 3 & $1.42 \mathrm{E}-05$ & $3.59 \mathrm{E}-07$ & $2.05 \mathrm{E}-05$ & $2.34 \mathrm{E}-05$ & $1.07 \mathrm{E}-05$ & $2.69 \mathrm{E}-07$ & $1.53 \mathrm{E}-05$ & $1.76 \mathrm{E}-0$ \\
\hline \multicolumn{3}{|c|}{ Total ADP kilogram antimony equivalents } & $5.03 \mathrm{E}-01$ & $2.07 \mathrm{E}-02$ & $1.29 \mathrm{E}+01$ & $2.69 \mathrm{E}+00$ & $1.24 \mathrm{E}+00$ & $5.68 \mathrm{E}-02$ & $1.14 \mathrm{E}+01$ & $2.32 \mathrm{E}+01$ \\
\hline
\end{tabular}

driven by demand, which for lower-value consumer goods tend to be more stable (Humphreys 2011).

Metal price indices tend to be dominated by iron ore, aluminum, and copper - all of which are used in final products that are relatively income elastic (i.e., changes in income result in disproportionate changes in metal demand). At the same time, short-term raw material supply is demand inelastic (i.e., production levels will persist to some extent and ride out shorter-term fluctuations in demand). Supply is demand inelastic in the short term due to the use of long-term businessto-business supply contracts and due to the large investments required to prove additional mineral resources and mineral reserves and expand supply. This is borne out by the fact that peaks and troughs in exploration expenditure invariably occur at times of high and low prices, respectively, rather than in anticipation of peaks and troughs in demand. Some regional effects, like the emergence of Chinese demand in the years 2003-2013, can have an even more important effect. So, raw material prices are volatile and will continue to be so in the future. They are directly impacted by less predictable socioeconomic movements, which do not lend themselves well to characterization in LCA.
Raw material supply is however more demand elastic in the long term. Slow and steady increases in supply capacity act to keep long-term average metal prices in check (see Figs. 1 and 2 above). Economic theory suggests that if supply failed to keep up with demand (e.g., because no further economic deposits could be found and recycling was not a viable alternative), the long-term average price of the raw material would increase until innovation provided a cheaper alternative material or technology. Such innovation is a reality in many metals and minerals markets, despite the fact that new deposits continue to be discovered and long-term average prices remain relatively steady. This reflects how easily substitutable most are in their main applications. For example, gold used to be used extensively in dental applications but has generally been replaced with lower-cost amalgam or resin materials through continuing technological advances. The fact that long-term average commodity prices corrected for inflation are fairly steady suggests that mineral resource figures are less affected by price fluctuations, but longer-term geopolitical influences and price cycles also exist and of course mineral resource figures change regularly as mineral exploration and extraction technologies progress. In fact, very often, mining companies assume that
Fig. 9 Comparison of products by ADP method, 2009 onward

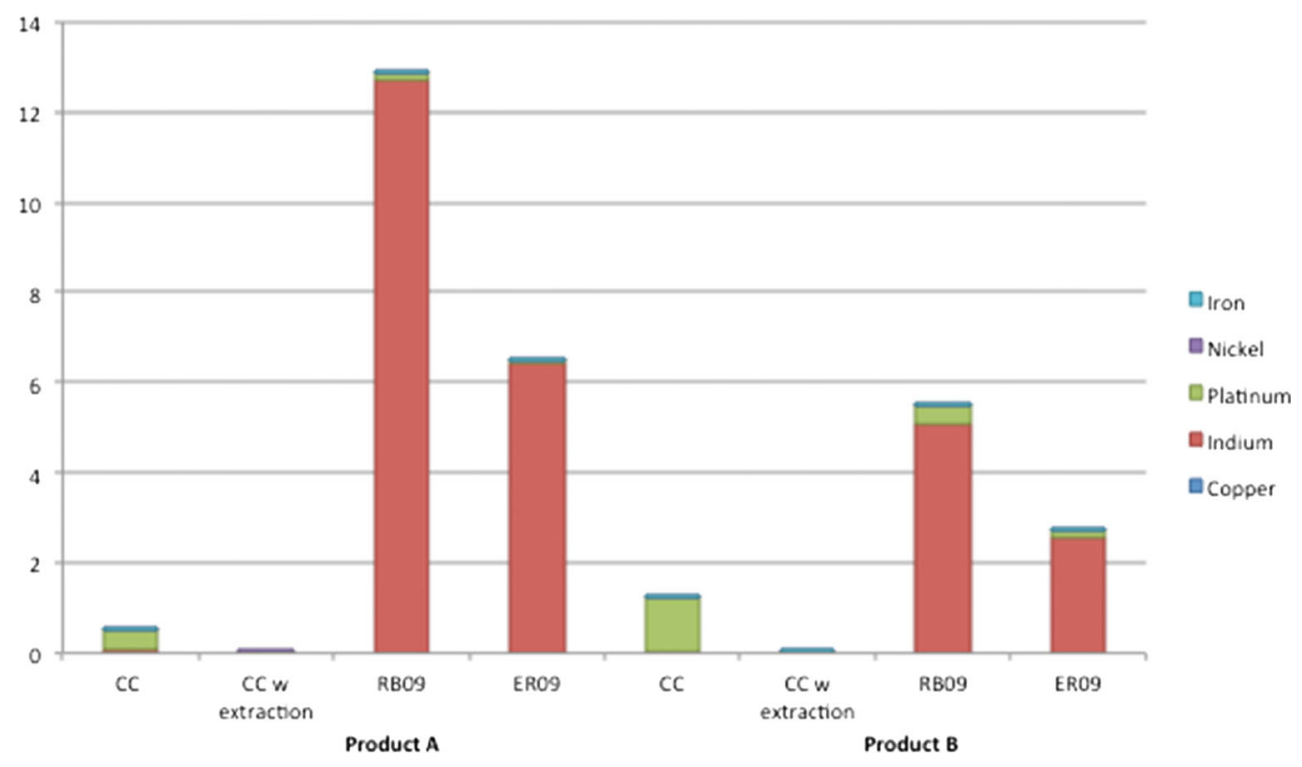


Table 4 Comparison of crustal concentration of major elements in weight percent oxide by source

\begin{tabular}{llll} 
Rank & Element & $\begin{array}{l}\text { Upper crust } \\
\text { composition in } \\
\text { percent (Clarke and } \\
\text { Washington 1924) }\end{array}$ & $\begin{array}{l}\text { Upper crust } \\
\text { composition in } \\
\text { percent (Rudnick } \\
\text { and Gao 2003) }\end{array}$ \\
\hline 1 & Silicon as $\mathrm{SiO}_{2}$ & 60.2 & 66.6 \\
2 & Alumina as $\mathrm{Al}_{2} \mathrm{O}_{3}$ & 15.7 & 15.4 \\
3 & Iron as $\mathrm{FeO}_{\mathrm{Total}}$ & 6.70 & 5.04 \\
4 & Calcium as $\mathrm{CaO}$ & 5.18 & 3.59 \\
5 & Sodium as $\mathrm{Na}_{2} \mathrm{O}$ & 3.92 & 3.27 \\
6 & Potassium as $\mathrm{K}_{2} \mathrm{O}$ & 3.19 & 2.80 \\
7 & Magnesium as $\mathrm{MgO}$ & 3.56 & 2.48 \\
8 & Titanium as $\mathrm{TiO}_{2}$ & 1.07 & 0.64 \\
9 & Phosphorus as $\mathrm{P}_{2} \mathrm{O}_{5}$ & 0.31 & 0.15 \\
10 & Manganese as $\mathrm{MnO}$ & 0.12 & 0.10
\end{tabular}

long-term commodity prices will tend toward long-term estimates of producers' cash costs (Humphreys 2011).

For these reasons, the contention that observed short-term raw material price trends are evidence of resource depletion cannot be relied upon. The weight of available evidence indicates that long-term average prices of raw materials have remained steady and that short-term trends are being driven by other unrelated factors. Commodity price trends, mineral reserve data, and mineral resources data are direct evidence of current resource availability and would be appropriate data, with which to attempt to gain some insight into possible resource availability constraints over different time frames. Insight into inter-generational resource availability will require use of real long-term average price trends and/or mineral resources - not short-term price fluctuations or mineral reserves.

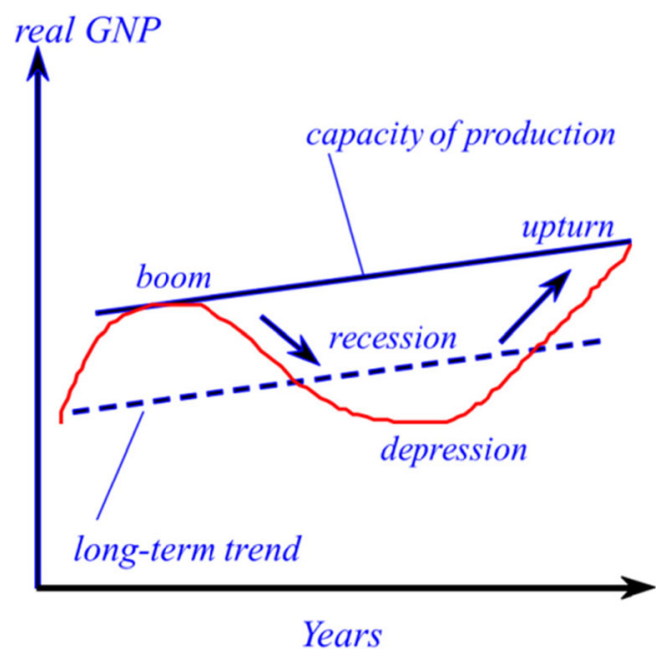

Fig. 10 Metal demand with economic cycles, adapted from Drnek (2007)

\section{The opportunity cost approach: grades and availability}

There are a number of LCIA methods that incorporate ore grades into their models, under the assumption that declining ore grades are indicative of resource depletion. This is problematic because grade is measured deposit by deposit and reported data only tells you what has been mined-it does not tell you about what will be mined at that deposit-or any other deposit - in the future. In fact, as will be demonstrated below, grades have so far been of limited relevance to the issue of availability because the growth in mine productivity has outstripped the economic effects of declining ore grades - in other words, ore grade declines seen today have been more a result of technological developments than a driver for them. Nearer term, the relationship becomes more complex. High commodity prices can also mean that lower ore grades can be worked economically. Thus, just as with technological development, ore grades can at once be a cause of higher prices and a result of them. This is most evident in the gold industry, where rising prices through the 2000s were accompanied by a significant decline in gold mine head grades (Humphreys D, personal communication, 2015).

West (2011) confirms that the decrease in copper grades seen in the last century was a result of companies innovating - advancing their ability to get more from less. He points to advances at Bingham Canyon Copper Mine in Utah at the turn of the twentieth century that enabled the mine to profitably extract from copper grades of less than $1.2 \%$ - essentially processing what would have been considered waste rock at that time. Now, with current drilling and sampling techniques, newly discovered deposits can be more accurately characterized at their larger limit and therefore mined with a completely different philosophy allowing them to be profitable at much lower grades.

It is generally in the interest of a company to continue mining an existing deposit, rather than find a new deposit, and a major part of the growth in mine output is provided by the expansion of existing mines. The sunken capital to establish a mine, processing plant, and transport infrastructure is significant. On the other hand, the social impacts of premature mine closure can be costly and challenging to manage. Companies will therefore continue to search for ways to extend the profitable life of a mine via technological innovations in mining, beneficiation, and refining of lower-grade ore. Several large mines have done just this and as a result have been operating for more than 100 years.

Furthermore, deposits are hidden and must be found through exploration - one can never know which deposits may be found in the future. For example, the ore grades of Canadian uranium mines have increased with time - from $1 \%$ or lower at Rabbit Lake, which opened in 1975 - up to $19.5 \%$ at McArthur River, which opened 24 years later (Hall and Coleman 2013; Raw Materials Group 2015). And the average iron content of 
ores mined in Western Australia and Brazil today is also much higher than the typical grades of iron minerals earlier processed in most of Western Europe (Crowson 2011b).

For these reasons, ore grade data should not be utilized to calculate resource depletion potential or even resource availability. The assumption that observed declines in ore grades are indicative of resource depletion cannot be relied upon as the weight of available evidence indicates that such declines are being driven by other unrelated factors and accompanied by significant increases in reserves.

\section{Context and the area of protection concept}

The concept of the area of protection (AOP) is a key foundation of LCIA, originally devised in the early 1990s, when the methodology was first established by the Society for Environmental Toxicology and Chemistry (Fava et al. 1993). Essentially, it is that part of the environment we are concerned about protecting when using an LCIA method. Meaningful LCIA requires an unambiguous AOP, a valid mechanism to link the studied product system to impacts on the AOP and a representative dataset. However, over the last 20 years, resource depletion methods have failed to meet these requirements.

When first established, the AOP "natural resources" were intended to capture the impact of reducing the amount of natural resources in the environment on long-term environmental sustainability (Fava et al. 1993). The intention was to convert the amount of a resource used by the system being studied into a result related to resource depletion. This description of the AOP is aligned with - and limited to - the fixed stock view that we refer to above. As discussed previously, when originally published by Guinée and Heijungs 1995, the method for estimating ADP utilized ultimate reserves (crustal content) to approximate the fixed stock. In 2001, the CML published a foundational textbook, "Handbook on life cycle assessment," which expanded the options for the impact category. It incorporated alternatives to the baseline of ultimate reserves, which included (1) economic reserves and extraction rates, (2) ultimate or economic reserves only (1/R), and (3) exergy. By introducing "economic reserves" (alternatives 1 and 2) into the equation, the method began to drift away from the AOP of natural resources and toward measuring economic availability. As is shown above, mineral reserves are far from fixed and this change of baseline actually signals a change of paradigm - from the fixed stock paradigm to the opportunity cost paradigm. To further complicate things, in 2002, van Oers et al. updated "alternative 1 " of the suggested methods by replacing economic reserves with the reserve base, thus making the reserve base the preferred alternative to the baseline method, rather than economic reserves, which became alternative 2 . This further exacerbated the problem, because although the reserve base is perhaps less fluctuating, it is also less accurate - thereby introducing even greater uncertainty into the original equation. Finally, in 2011, the ILCD project of the European Commission Joint Research Centre endorsed the use of the reserve base in the denominator as the recommended method for Europe, replacing ultimate reserves, which had until then been defined as the baseline method.

This misalignment of the intended AOP with the actual AOP is a common problem across many LCIA methods intended to estimate resource depletion, not just the CML method. Table 5 demonstrates the misalignment that remains today, listing several commonly referred to LCIA methods with their intended AOP and actual AOP.

By comparing the "intended area of protection" with the "actual area of protection," it is apparent that the only LCIA method that remains true to its intended AOP is ADP using Guinee and Heijungs (1995). This is because the majority of the methods have shifted away from geological modeling of total stocks of natural resources and gone toward the use of economic statistics that are collected to inform economic actors about resource availability for human use. Van Oers et al. pointed this out in 2002, "The disadvantage of the reserve base and economic reserve is that the estimate of the size of the reserve involves a variety of, respectively, technical and economic considerations not directly related to the environmental problem of resource depletion."

All of this is not to say that the area of protection could not be redefined to align with the opportunity cost view. Sonnemann et al. (2015) have started to do this, with a first proposal for integration of economic and social impacts into life cycle sustainability assessment, which now needs vetting across disciplines. If we want to understand the availability of a material on the 10-30-year time horizon, versus physical depletion on a 300-year time horizon, our methods willand should - contrast significantly.

\section{Toward an opportunity cost approach}

\subsection{Short-term availability}

Schneider et al. (2013) recently published a method called "economic scarcity potential" as a beginning basis for advanced opportunity cost assessment of raw materials in the LCIA framework. Although the method is in its infancy-its structure provides a basis for how a complementary tool might assess availability along with LCA results, and from Schneider et al. choice of economic criteria, we suggest the economic scarcity potential (ESP) method is assessing shortterm availability. In this case, the authors are most concerned about what could possibly cause a supply disruption in vehicle manufacturing. The authors suggest that they are expanding the AOP natural resources to include the potential for economically or socially derived scarcity, but we would argue that 
Table 5 Intended versus actual AOP for select methods

\begin{tabular}{|c|c|c|c|}
\hline Method & Intended area of protection & Actual area of protection & Data used \\
\hline ADP (Guinée and Heijungs 1995) & Depletion of non-renewable resources & $\begin{array}{l}\text { Long-term depletion } \\
\text { of (primary) abiotic } \\
\text { resources }\end{array}$ & $\begin{array}{l}\text { Average crustal concentration, } \\
\text { volume of the continental } \\
\text { crust, and production }\end{array}$ \\
\hline $\begin{array}{l}\text { ADP (Van Oers et al. 2002) } \\
\text { alternatives } 1 \text { and } 2\end{array}$ & Depletion of non-renewable resources & $\begin{array}{l}\text { Medium-term availability } \\
\text { of resources }\end{array}$ & $\begin{array}{l}\text { Mineral resources and mineral } \\
\text { reserves }\end{array}$ \\
\hline $\begin{array}{l}\text { EDIP (Hauschild and } \\
\text { Wenzel 1998) }\end{array}$ & Depletion of non-renewable resources & $\begin{array}{l}\text { Short-term availability } \\
\text { of resources per person }\end{array}$ & Mineral reserves \\
\hline $\begin{array}{l}\text { Exergy (Finnveden and Östlund } \\
\text { 1997; Dewulf et al. 2007) }\end{array}$ & $\begin{array}{l}\text { Environmental and socioeconomic } \\
\text { efficiencies of resource use }\end{array}$ & $\begin{array}{l}\text { "Natural" stocks and } \\
\text { flows of exergy }\end{array}$ & Exergy co-efficients \\
\hline $\begin{array}{l}\text { IMPACT } 2002 \text { (Jolliet et al. 2003) } \\
\text { and EI99 (Goedkoop and } \\
\text { Spriensma 2001) }\end{array}$ & Depletion of non-renewable resources & $\begin{array}{l}\text { Medium-term availability } \\
\text { of resources in current } \\
\text { fleet of mines }\end{array}$ & Processed ore grades \\
\hline ReCiPe (Goedkoop et al. 2009) & $\begin{array}{l}\text { Damage to resource availability_-"additional } \\
\text { net present costs that society has to } \\
\text { pay as a result of an extraction" }\end{array}$ & $\begin{array}{l}\text { Medium-term availability } \\
\text { of resources in current } \\
\text { fleet of mines }\end{array}$ & $\begin{array}{l}\text { Processed ore grades and fuel } \\
\text { prices }\end{array}$ \\
\hline AADP (Schneider et al. 2011) & Depletion of non-renewable resources & $\begin{array}{l}\text { Medium-term availability } \\
\text { of resources }\end{array}$ & $\begin{array}{l}\text { Mineral resources and } \\
\text { anthropogenic stocks }\end{array}$ \\
\hline AADP (Schneider et al. 2015) & Depletion of non-renewable resources & $\begin{array}{l}\text { Medium-long term } \\
\text { availability of resources }\end{array}$ & $\begin{array}{l}\text { Ultimately extractable reserve } \\
\text { estimations and } \\
\text { anthropogenic stocks }\end{array}$ \\
\hline
\end{tabular}

because it is a complementary assessment tool, the concept of AOP in its traditional "protection" sense no longer applies. What the ESP actually serves to protect is the product system itself rather than any natural resource.

The ESP method utilizes a list of economic and social factors that have been studied in the literature and are either known or assumed to affect resource availability. These criteria are broad, including everything from trade barriers to social acceptance of mining activities. Factors selected include reserves, recycling, country and company concentration of mining activity, economic stability, demand growth, trade barriers, and companion metal fraction. The authors use a distance-to-target method based on Frischknecht et al. (2008), which employs a threshold, above which high risk in supply is expected. The result is determined by a ratio of the current indicator value to the threshold multiplied by the LCI result. The current method weights all impact factors equally when summed to an overall "ESP"; however, an organization may choose to apply weighting of its own. One of the great advantages of this method is that not only can weighting criteria be tailored to an organization's needs but the thresholds for each impact factor must be determined by the organization (e.g., different country governance thresholds may prove useful for specifically addressing individual geopolitical risks such as that posed by so-called conflict minerals). Provided that the organization is diligent about vetting its selected risk thresholds, it will be able to ensure that the results are meaningful.

In our view, the impact factors and accompanying thresholds proposed can be improved by incorporating some of the lessons learnt from the ongoing development of the European Union's Criticality Assessment Methodology. However, rather than a detailed critique of the ESP method, our purpose here is to point to its potential as a first step in a more useful direction for assessing the short-term availability of resources. Figure 11 (reproduced from Schneider et al. 2013) demonstrates how the ESP results can be more useful than LCIAbased resource depletion results. While the ADP (crustal content incl. extraction) results highlight platinum group metals (PGM) and gold as the most significant contributors to resource depletion in the very long term, ESP highlights PGM
Fig. $11 \mathrm{ESP}_{\text {global }}(l e f t)$ versus $\mathrm{ADP}_{\text {ultimate reserves }}$ (right) reproduced with permission from Schneider et al. (2013)
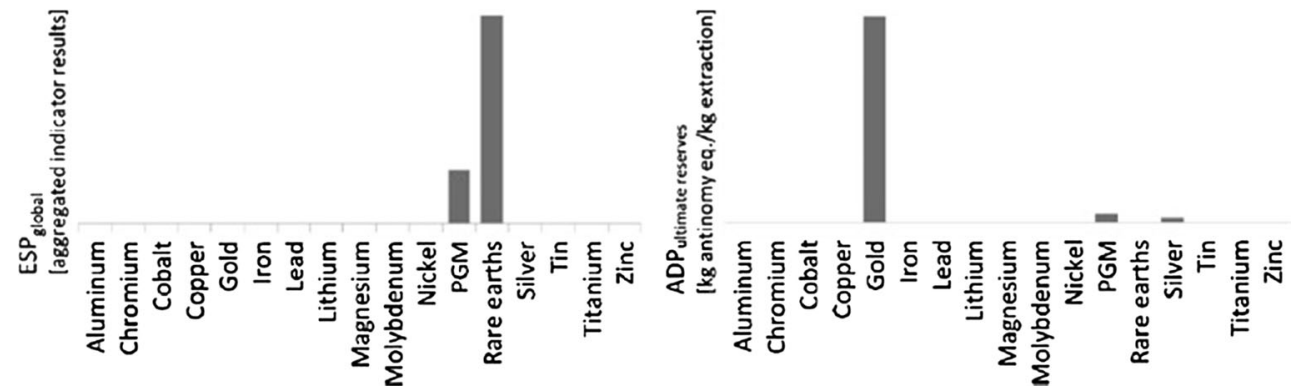
and rare earth elements as the most significant short-term risks from an economic scarcity perspective. The user can then take these results, and a more detailed ranking of materials, to further investigate the implications for decision-making or product design. Note that the units in the two charts are different and therefore not directly comparable.

Thus, although the method requires development, it provides a framework from which the short-term opportunity cost view of availability can be assessed, given that appropriate impact factors and thresholds are set. Note that ESP assesses short-term economic conditions impacting the product system as opposed to the impacts of the product system on short-term availability of resources - and we would contend that it is very difficult for a single product system to influence the short-term global availability of a commodity from the demand side. Potential supply side constraints are of far more interest to most decision-makers.

\subsection{Long-term availability}

While a method such as ESP provides a basis for understanding where availability risks present themselves for individual materials in the 10-20-year time frame, other methods must be sought for the $30+$ year time frame. To address this knowledge gap, Tilton defined the "cumulative availability curve" (CAC) to explore the long-run availability of minerals and the threat of resource depletion (Tilton 2002). As opposed to a conventional supply curve which indicates how much of a commodity will be supplied during a given time period, the CAC attempts to capture how much of a mineral is economically available over all time at various prices, making the conservative assumption that all determinants of supply remain fixed at current or given levels. The concept is still in its infancy, but calculations are published for lithium, oil and gas, and others are underway (Tilton 2002; Yaksic and Tilton 2009; Aguilera et al. 2009). The shape of the curve can give us insight into future availability for individual minerals, albeit assuming continuation of the given demand, economic context, geopolitical context, etc. As shown in Fig. 12, if the slope of the resulting curve changes gradually, new technology can be relied upon to keep up with demand (as higher prices and costs will trigger the need for innovative alternatives). When the curve is relatively flat, it indicates that resource availability is not likely to be an issue except perhaps due to unforeseen political events - like a world war. Where there are either discontinuities or sharply rising costs across different mineral occurrences in the curve, there may be resource availability concerns associated with the assumed conditions that may warrant further investigation and/or for which innovations may be required.

For example, a recent cumulative availability curve calculated for lithium, shown in Fig. 13 below (Yaksic and Tilton

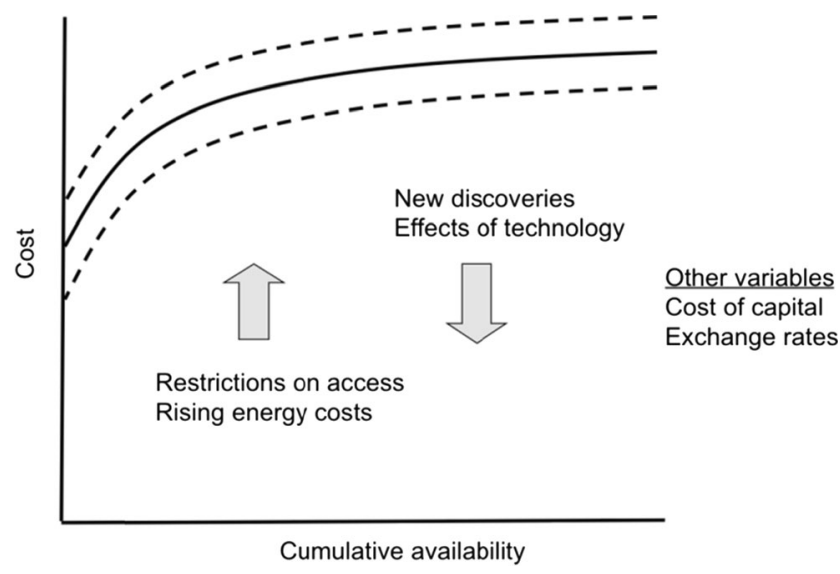

Fig. 12 The cumulative availability curve, adapted from Tilton and Skinner (1987), Tilton (2002), and Humphreys (2013)

2009), has a gentle slope on its left-hand side, and a steeper one to the right, due to the assumed costs for technology required to extract lithium from seawater. The latter were estimated from a study conducted in the 1970s when researchers investigated adapting brine extraction technology (commonly used now for lithium production) to extracting lithium from seawater (Steinberg and Dang 1975). However, the steep slope occurs at a price not far from today's price, and further to the right the curve once again flattens out, indicating that resource availability will not pose a significant threat to society unless political circumstances change. It is important to note that this curve is incomplete, due to the fact that the amount of lithium that could be extracted from seawater is massive $-44.8 \times 10^{9} \mathrm{t}$, which would extend the curve by a thousand fold (Yaksic and Tilton 2009). Seawater becomes economical for extraction between 7 and $10 \$$, as indicated by the curve scenarios. Thus, the scenario lines could continue almost indefinitely after that point.

Results from CACs developed to date confirm that technological advances associated with extraction offset upward pressure on costs in the long term. As a result, these curves have tended to shift downward with each update of the curve over time. Further, in some cases, these advances have more than offset cost increases, suggesting growing, rather than declining availability of the resource. Thus, one can see that if an assessment using an ESP type approach highlights supply risk associated with a particular material, a CAC can assist in understanding the plausible longer-term availability.

One drawback of the $\mathrm{CAC}$ is the data required to generate it - the curve for lithium took approximately 1.5 years by a Master's student (Tilton JE, personal communication, 2015). In addition, the uncertainty of the impact of technology, future production costs, and future demand are significant variables. However, these curves can shed some light on whether there are real threats to resource availability in the longer term under foreseeable conditions. 
Fig. 13 Cumulative availability curves for lithium. Reproduced with permission from Yaksic and Tilton (2009)

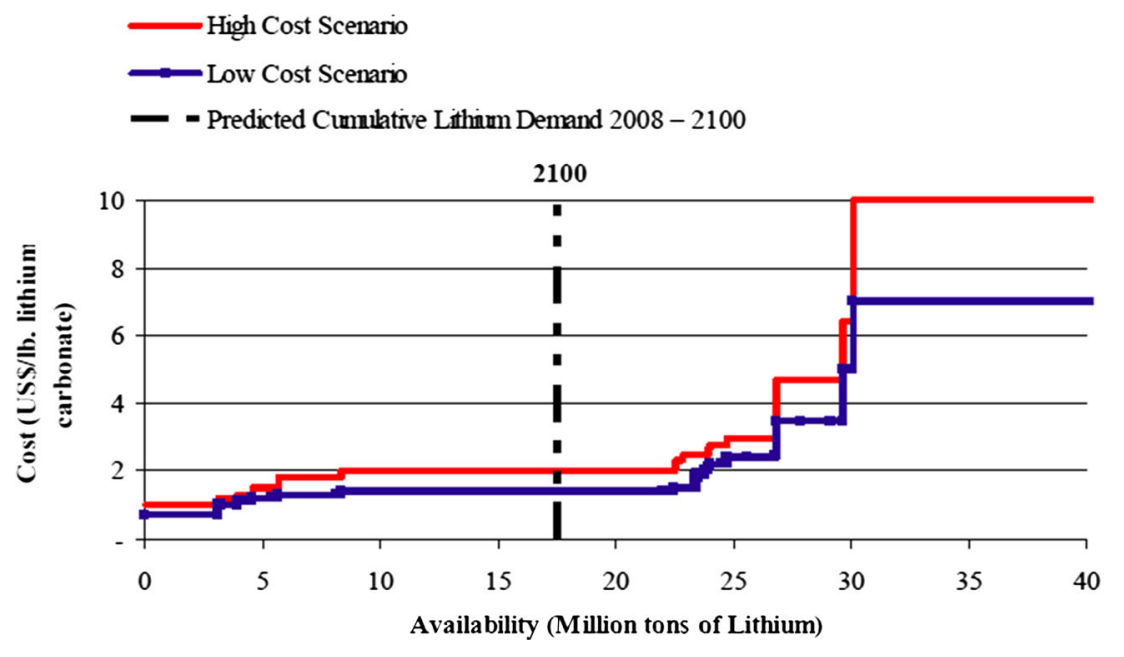

\section{Discussion}

Going forward, any work on resource depletion needs to have a very clear objective. Until then, tool developers should proceed cautiously. Due to lack of clarity on the AOP, the overall objective, and therefore the data and parameters that should be utilized, recent model developments have not been able to reduce certainty or improve results. LCIA may be suited to assessing resource depletion potential from the fixed stock view, but it appears that most decision-makers, stakeholders, and researchers would actually like to better understand resource availability from a life cycle perspective. Similarly, there is confusion about impacts of products and sectors on availability (competitive use of scarce resources) and availability factors impacting upon products and sectors (supply risk). Underlying all of this confusion are differences in definitions of critical terminology that need to be clarified so that the LCA and mineral industries understand a common language. In our view, the industry standard for reporting defined above (CRIRSCO 2013) should take precedence, as these have been agreed upon globally by stakeholders and are used to guide reported data.

As we have shown above, processed ore grades (though reported by mining companies and therefore relatively accessible for use) do not provide useful information about either resource depletion or resource availability. Theories that use reported ore grades to suggest that a mineralogical barrier to production will 1 day be reached suffer from a number of fundamental flaws. Firstly, such theories rely on the assumption that all mineral deposits are mined out in order of decreasing grade, which (a) would require a priori knowledge of all existing mineral deposits by all mining companies and (b) is not borne out by the historical record. It is impossible with today's technologies to know the exact location, quantity, and quality of all mineral deposits globally. Mineral exploration and discovery is still a vitally important and difficult job. Still, for the few commodities where average declines in ore grade have been observed (e.g., copper), they have been accompanied by truly massive increases in economic reserves. Therefore, methods that use ore grade as a key variable — such as IMPACT2002, Eco-Indicator99, and ReCiPe-for calculating resource impacts do not provide a satisfactory path forward.

van Oers et al. (2002) recommend a sensitivity analysis using the different denominators when interpreting the results from a study using ADP. For the average LCA practitioner, or purchaser reviewing an Environmental Product Declaration (EPD), this is not likely to happen. Instead, a single result will be evaluated and an incorrect decision may be made. The EU's current Product Environment Footprint project, for example, does not specify the use of sensitivity analysis when considering LCIA methods - only when considering different sources of data. It has preliminarily specified the use of ADP (van Oers et al. 2002), using the USGS reserve base estimate from 1999, but this is a particularly poor choice when attempting to inform consumers about the potential long-term environmental impact of their purchasing decisions, particularly given the rise of Chinese demand in subsequent years.

Using outdated estimates of highly unstable indicators coupled with a method with very low agreement globally among experts is not appropriate in a policy context. How can we be sure we are headed to a more sustainable, resource efficient world when we are basing decisions on such changeable results? Is it really better to have something than nothing when it comes to assessing the potential environmental impact of a product or system? Where policy and purchasing decisions are being made, and therefore markets impacted, we would argue it is not. As discussed above, much of this confusion and uncertainty stems from an unclear AOP on which the models are built, which several other authors have confirmed to date.

At its most basic, if we assess the most commonly used method-ADP (van Oers et al. 2002) - as recommended in the ILCD Handbook (using the reserve base), we can easily see that it does not meet the majority of the recommended 
criteria set out by International Organization for Standardization (ISO) 14044 (ISO 14044 2006, p. 19) for impact category selection. In particular, as discussed previously, there is no broad agreement on characterization methods for the area of protection natural resources. The recommended method is not, in fact, environmentally relevant, because it uses calculated resource data that is economic in nature and variable on an annual time frame. The ILCD Handbook pairs the CML 2002 reserve base method with USGS reserve base data, although the two organizations' definitions of reserve base do not match. Further to this point, it has no "distinct identifiable environmental mechanism." Instead, it is simply an indicator of a product's required inputs versus dated reserve data, developed for economic purposes. In fact, there is no empirical environmental observation from this indicator whatsoever.

If we are truly concerned about resource availability in the multi-generation context, then we must completely re-assess the best contribution of LCA. Availability is a concept measured by economics, impacted by a multitude of factors discussed here, including market demand, the anthropogenic stock, exploration, political stability, and the states of the global and regional economies. It is not a concept that is strongly influenced by individual product systems and is not measured by LCA. As a result, key questions that remain include should LCA be modified to be able to measure availability? Or should we look outside LCA altogether? As is shown above, the results of LCA must be paired with other methods to realistically assess the constraints associated with short-term availability or a product's potential contribution to reduced long-term availability.

\section{Recommendations}

First, we must acknowledge that the majority of environmental issues associated with mining are well captured in the other LCIA categories for which there are globally and regionally appropriate and accepted impact category methods. These include characterizing the impacts associated with issues such as emissions from mining and refining that contribute to climate change, smog, acid rain, and eutrophication. Additionally, if end-of-life modules are well constructed, the environmental benefits of the inherent recyclability of metals are well captured by the tool.

Second, it is important to be clear about the view from which we come when attempting to define and measure resource depletion. In our view, fixed stock parameters such as crustal content are the only measures for estimating mineral depletion that fit within the logical construct of life cycle assessment as it is currently standardized by ISO 14040 series of standards. This might at least have the academic merit of being consistent with LCA principles and what we know about the occurrence of minerals in nature and could serve to allay any lingering doubts that stakeholders might have about resource depletion potential. However, opportunity cost measures such as mineral resources and reserves, prices, and production costs are more applicable in the context of understanding mineral demand and availability, which from an industry perspective (and it seems from the perspective of recent method developers) is far more worthy of policy-makers' time and attention. This was also the consensus view of stakeholders at the conclusion of the MMSD project over 10 years ago (IIED 2002). Decision-makers should look to economists, the market, and society in general, for broader assessments that consider shorter-time horizons.

\subsection{Integrating opportunity cost into life cycle sustainability assessment}

As discussed in detail above, the opportunity cost view of resource availability requires a different set of variables and tools than the fixed stock view of depletion. Traditionally, these tools are not developed by LCA practitioners but by mineral economists and geologists. However, because critical raw materials have come into focus in recent years, interest has shifted toward developing an area of protection and method for introducing concerns with availability into LCA. The economic scarcity potential of Schneider et al. (2013) is an example of this. However, its application is context or study specific - the results are not comparable outside an individual study (within an organization) and it describes potential constraints on an organization's production, rather than potential impacts of its production on resource availability. Yet, its approach is a step in the right direction, enabling the practitioner to compare trade-offs in environmental impacts as well as those economic and social in nature, from the same life cycle inventory. In addition, complementary tools such as the CAC can shed light on the availability of critical minerals in the future - and what potential changes in availability might occur as demands shift and technologies develop. Looking to other tools provided by - and utilized in - industry is necessary to bridge the gap between the capabilities of LCA and the desired broader view of sustainable development with regard to minerals and metals. The industry is experienced in making plausible assumptions about the future costs of power, labor, reagent, and machinery inputs; long-term price forecasting; and compilation of production costs and construction of cash cost curves, e.g., using data published in financial statements or held in commercial databases, such as

- Mining and Metals Sector Supplement of the Global Reporting Initiative 
- ICMM Reporting and Assurance System, www.icmm. com

- Towards Sustainable Mining System of the Mining Association of Canada

- SNL Metals and Mining, www.snl.com

- Brook Hunt and Wood Mackenzie, www.woodmac.com

- CRU, www.crugroup.com

- AME Mineral Economics (Australia), www.ame.com.au

- Bloomsbury Mineral Economics (UK), www. bloomsburyminerals.com

A simple way to determine what tool is most appropriate in the case of life cycle sustainability assessment is by considering the time frame in which one desires to understand the impacts of a product system or risks to the product system. When defining the goal and scope of a life cycle study, the practitioner evaluates which impact categories should be included in the assessment to understand the potential impacts of the product on the environment. We can take this and expand it to incorporate potential impacts on resource availability or depletion related to the product. For example, if the decision-maker is concerned about availability of resources in the next 10-20 years, tools such as the adapted ESP model or criticality (or some hybrid thereof) may be the most suitable complementary tools available today. As CACs are developed for more and more materials, their results can be utilized to analyze individual materials in the 30-100-year time frame. Alternatively, if the user is simply interested in the very nearterm implications of material selection, say on the 1-3-year time frame, they may simply pair analyst reports with output from an LCA. Or, it may be that the decision-maker wants to understand a range of relevant time frames for a given resource or product system and therefore utilizes each of the tools in complementary fashion. Finally, ADP using crustal content can be used to assess potential depletion impacts to a fixed stock in the very long term, but it is not an appropriate tool for a decision-maker. Figure 14 provides a visual of this time frame decision tool.

\section{Conclusions}

Many organizations and scientists have attempted to characterize resource depletion in LCIA, including the Society of Environmental Toxicology and Chemistry (SETAC) (Udo de Haes et al. 1999) and the UNEP-SETAC Life Cycle Initiative (e.g., Jolliet et al. 2004). None has resulted in a uniform globally accepted set of characterization models and factors. As a result, depletion potential results are highly variable across models. Mancini et al. (2013), Hauschild et al. (2013), and Klinglmair et al. (2013) have all recently highlighted again the need for these models to be further refined, before being fit for any formal decision-making, let alone direct product to product or system to system comparisons being touted by green building schemes and other government initiatives. In fact, it has been argued previously that resource depletion does not belong at all in LCA — an inherently environmental tool cannot do justice to a problem that is sociopolitical and economic in nature (van der Voet 2013).

There are many reasons for this - the most critical being that is accurately capturing and calculating resource depletion in LCA is relatively easy but not seen by stakeholders as meaningful. Intra-generational and inter-generational availability of resources is an issue of more general concern and driven by demand, politics, markets, and technology. The theoretical environmental constraint, as it has been characterized in the AOP in LCA to date- is in our view so remote as to be of little policy or market relevance. Existing and future economic resource constraints are obviously of great policy and market relevance, but LCA has to date done such a poor job of characterizing them that it has only triggered controversy, misunderstandings, and misleading claims. As a result, the added value of its inclusion in LCA so far has been minimal.

Sustainable supply is a socioeconomic issue — one affected by sudden shifts in demand, political instability, advances in mining technology, new discoveries of deposits, access to land, etc. - not easily captured by the process of characterization in LCIA. Instead, economic factors must be investigated
Fig. 14 Depletion and availability assessment tools by applicable time frame

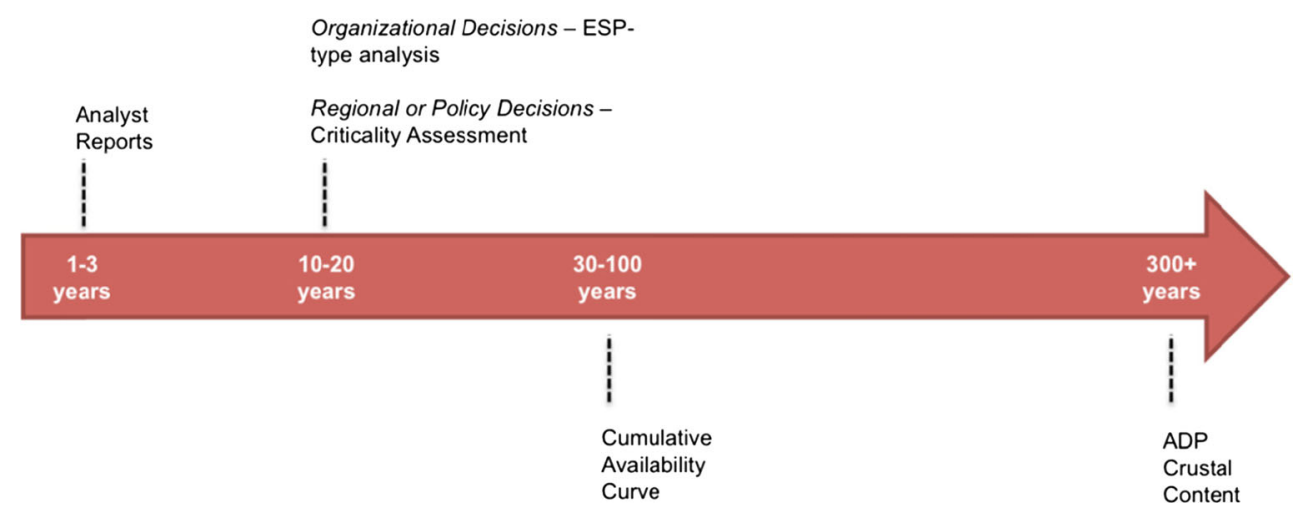


separately — but in parallel—via forecasting tools designed to give us a "window in" to the future of mineral availability. This view will allow us to better understand the important trade-offs that may exist when evaluating the five forms of capital that are critical to decision-making in the context of sustainable development - natural, manufactured, human, social, and financial capital: LCA as a tool is not designed to address changes over time - let alone sociopolitical responses over time - it represents a "snapshot" of potential environmental impacts for a given functional unit. Moving toward the use of other tools to address the gaps left by LCA regarding mineral resources is critical to supporting better decision making; giving due consideration to both the fixed stock and opportunity cost concerns and ensuring decisions actually contribute to a more sustainable future.

Acknowledgments This paper has been developed over 4 years of discussions with exploration, geology, and economic experts within the metal and mining industries globally as well as with LCA experts, including during workshops hosted by the European Association of Mining Industries, Metal Ores and Industrial Minerals (Euromines), and the International Council on Mining and Metals (ICMM). The authors thank all the experts for taking part in these discussions and for information that has contributed to this paper. In particular, we are grateful for the assistance provided by Boliden AB, Prof. John E Tilton PhD, Dr. David Humphreys, Freeport McMoran Inc., International Copper Association Ltd., ICL Fertilizers Group, Lulea Technical University, the Montan Universität Leoben, Newmont Mining, Raw Materials Data, Rio Tinto Limited, United States Geological Survey, and Prof Jo Dewulf PhD. Additionally, we would like to acknowledge funding assistance from The Cobalt Development Institute, International Aluminium Institute, International Lead Association, International Molybdenum Association, International Stainless Steel Forum, International Tungsten Industry Association, and the International Zinc Association.

Open Access This article is distributed under the terms of the Creative Commons Attribution 4.0 International License (http:// creativecommons.org/licenses/by/4.0/), which permits unrestricted use, distribution, and reproduction in any medium, provided you give appropriate credit to the original author(s) and the source, provide a link to the Creative Commons license, and indicate if changes were made.

\section{References}

Aguilera RF, Eggert RG, Lagos G, Tilton JE (2009) Depletion and the future availability of petroleum resources. Energy J 30(1):141-174

Annema JA, van den Hoek PWM, Ros JPM (1993) De aarde als onze provisiekast, een inventarisatie van voorraden en hun onderlinge samenhang. Report 772416001 National Institute of Public Health and Environmental Protection, Bilthoven, The Netherlands

Boliden (2012) Press release. http://www.boliden.com/fi/Press/News/ 2012/New-Copper-Discovery-/. Accessed: 16 Feb 2015

Clarke FW, Washington HS (1924) The composition of the Earth's crust. USGS Professional Paper 127, 117 pp

Committee for Mineral Reserves International Reporting Standards (CRIRSCO) (2013) International Reporting Template for the public reporting of exploration results, mineral resources and mineral reserves. ICMM (International Council on Mining \& Metals), London. Available at http://www.crirsco.com/crirsco_template_v2.pdf
Crowson CF (2011a) Economics of the Minerals Industry in SME Mining Engineering Handbook 3rd Edition. In: Darling P (ed) Society for Mining, Metallurgy, and Exploration, Inc

Crowson PCF (2011b) Mineral reserves and future minerals availability. Mineral Economics Raw Materials Report ISSN 2191-2203. doi 10. 1007/s13563-011-0002-9

Dewulf J, Boesch ME, de Meester B, van der Vorst G, van Langenhove H, Hellweg S, Huijbregts AJ (2007) Cumulative Exergy Extraction from the Natural Environment (CEENE): a comprehensive life cycle impact assessment method for resource accounting. Environ Sci Technol 41(24):8477-8483

Drnek T (2007) Introduction to Montan Universität lectures on mineral economics. Leoben, Austria

EC-JRC (2011) ILCD handbook. Recommendations based on existing environmental impact assessment models and factors for life cycle assessment in European context. IES, Joint Research Centre, Ispra. Available at http://lct.jrc.ec.europa.eu

Erickson RL (1973) Crustal abundance of elements, and mineral reserves and resources. In: Brobst DA, Pratt WP (eds) United States mineral resources: US Geological Survey professional paper 820. US Government Printing Office, Washington, pp 21-25

European Union (2013) Commission recommendation of 9 April 2013 on the use of common methods to measure and communicate the life cycle environmental performance of products and organisations (2013/179/ EU). Off J Eur Union 56

European Commission (2014) Communication from the commission to the European Parliament, the Council, the European Economic and Social Committee and the committee of the regions on the review of the list of critical raw materials for the EU and the implementation of the raw materials initiative: COM/2014/0297 final

Fava JA, Consoh F, Demson R, Dickson K, Mohin T, Vigon B (eds) (1993) A conceptual framework for life cycle impact assessment. Society for Environmental Toxicology and Chemistry, Pensacola

Finnveden G, Östlund P (1997) Exergies of natural resources in life-cycle assessment and other applications. Energy 22(9):923-931

Fleischer M, Parker RL (1967) Composition of the Earth's crust. In Data of Geochemistry, Sixth Edition, USGS Paper 440-D. United States Government Printing Office, Washington DC

Frischknecht R, Steiner R, Jungbluth N (2008) Oekobilanzen - methode der oekologischen Knappheit — Oekofaktoren 2006. BAFU, Zurich

Gee A (2014) The rare-earths roller coaster. The New Yorker. http://www. newyorker.com/business/currency/the-rare-earths-roller-coaster. Accessed 8 Mar 2015

Goedkoop M, Spriensma R (2001) The Eco-indicator 99: a damage oriented method for life cycle impact assessment-methodology report. PRe Consultants, Amersfoort

Goedkoop M, Heijungs R, Huijbregts M, de Schryver A, Struijs J, van Zelm R (2009) ReCiPe 2008. A life cycle assessment method which comprises harmonized category indicators at the midpoint and the endpoint level. Report I: characterisation. Ministry of Housing, Spatial Planning and Environment, Amsterdam

Graedel et al (2011) Estimating long-run geological stocks of metals. UNEP International Panel on Sustainable Resource Management; Working Group on Geological Stocks of Metals. Working paper, June 11, 2011

Guinée JB (1995) Development of a methodology for the environmental life-cycle assessment of products, with a case study on margarines. Institute of Environmental Sciences, Leiden, thesis, $225 \mathrm{pp}$

Guinée J, Heijungs R (1995) A proposal for the definition of resource equivalency factors for use in product life-cycle assessment. Environ Toxicol Chem 14(5):917-925

Hall S, Coleman M (2013) Critical analysis of world uranium resources: U.S. Scientific Investigations Report 2012-5239, $56 \mathrm{p}$

Hauschild M, Wenzel H (1998) Environmental assessment of products, vol 2-Scientific background. Chapman \& Hall, UK 
Hauschild MZ, Goedkoop M, Guinée J, Heijungs R, Huijbregts M, Jolliet O, Margni M, de Schryver A, Humbert S, Laurent A, Sala S, Pant R (2013) Identifying best existing practice for characterization modelling in life cycle impact assessment. Int J Life Cycle Assess 18(3): 683-697

Herrington R (2013) Road map to mineral supply. Nature Geoscience Vol 6 November, pp 892-894

Humphreys D (2011) Pricing and trading in metals and minerals in SME mining engineering handbook 3rd Edition. In: Darling P (ed) Society for Mining, Metallurgy, and Exploration, Inc

Humphreys D (2013) Long-run availability of mineral commodities. Miner Econ 26(1-2):1-11

IIED (2002) Breaking new ground: the report of the Mining, Minerals, and Sustainable Development project. Earthscan Publications Ltd, London

ISO (2006) ISO 14044. Environmental management-life cycle assessment-requirements and guidelines. International Organization for Standardization, Geneva

Johnson KM, Hammarstrom JM, Zientek ML, Dicken CL (2014) Estimate of undiscovered copper resources of the world, 2013: U.S. Geological Survey Fact Sheet 2014-3004, 3 p

Jolliet O, Margni M, Charles R, Humbert S, Payet J, Rebitzer G, Rosenbaum R (2003) IMPACT 2002+: a new life cycle impact assessment methodology. Int J Life Cycle Assess 8(6):324-330

Jolliet et al (2004) The LCIA midpoint damage framework of the UNEP/ SETAC life cycle initiative. Int J Life Cycle Assess 9(6):394-404

Kesler S, Wilkinson B (2008) Earth's copper resources estimated from tectonic diffusion of porphyry copper deposits. Geology 36(3):255-258

Klinglmair M, Sala S, Brandão M (2013) Assessing resource depletion in LCA: a review of methods and methodological issues. Int J Life Cycle Assess 19:580-592

Mancini L, De Camillis C, Pennington D (eds) (2013) Security of supply and scarcity of raw materials. Towards a methodological framework for sustainability assessment. European Commission, Joint Research Centre, Institute for Environment and Sustainability, Publications Office of the European Union, Luxemburg

Merriam-Webster (2015) Online dictionary. Merriam-Webster, Incorporated. http://www.merriam-webster.com. Accessed 26 May 2015

Ostin B (2013) Radioactive mountain is key in US rare-earth woes. Live Science. http://www.livescience.com/37356-heavy-rare-earthmining-america.html. Accessed 8 March 2015

Raw Materials Group (2015) SNL Metals \& Mining Database. www.snl. com/Sectors/MetalsMining/Default.aspx. Accessed 15 Apr 2015

Rudnick RL, Gao S (2003) Composition of the continental crust. In: Rudnick RL (ed) The crust, vol. 3. Elsevier, pp 1-64

Schneider L, Berger M, Finkbeiner M (2011) The anthropogenic stock extended abiotic depletion potential (AADP) as new parameterization to model the depletion of resources. Int J Life Cycle Assess 16(9): 929-936
Schneider L, Berger M, Schüler-Hainsch E, Knöfel S, Ruhland K, Mosig J, Bach V, Finkbeiner M (2013) The economic resource scarcity potential (ESP) for evaluating resource use based on life cycle assessment. Int J Life Cycle Assess 19:601-610

Schneider L, Berger M, Finkbeiner M (2015) Abiotic resource depletion in LCA - background and update of the anthropogenic stock extended abiotic depletion potential (AADP) model. Int J Life Cycle Assess 20:709-721

Sonnemann G, Gemechu ED, Adibi N, De Bruille V, Bulle C (2015) From a critical review to a conceptual framework for integrating the criticality of resources into life cycle sustainability assessment. J Clean Prod 94:20-34

Steinberg M, Dang V (1975) Preliminary design and analysis of a process for the extraction of lithium from seawater, Technical Report 20535R: Upton. Brookhaven National Laboratory, NY

Tilton JE (2001) Depletion and the long-run availability of mineral commodities. Workshop on the Long-Run Availability of Mineral Commodities sponsored by the Mining, Minerals and Sustainable Development Project and Resources for the Future in Washington, DC, April 22-23

Tilton JE (2002) On borrowed time? Assessing the threat of mineral depletion: Washington, DC, Resources for the Future, p 1-158

Tilton JE, Lagos G (2007) Assessing the long-run availability of copper. Resour Policy 32:19-23

Tilton JE, Skinner BJ (1987) The meaning of resources. In: Skinner BJ, McLaren DJ (eds) Resources and world development. Wiley, New York, pp 13-27

Udo De Haes HA, Jolliet O, Finnveden G et al (1999) Best available practice regarding impact categories and category indicators in life cycle impact assessment. Int J Life Cycle Assess 4:66-74

van der Voet (2013) Criticality and abiotic resource depletion in life cycle assessment. Chapter in: Mancini L, De Camillis C, Pennington D (eds) Security of supply and scarcity of raw materials. Towards a methodological framework for sustainability assessment. European Commission, Joint Research Centre, Institute for Environment and Sustainability, Publications Office of the European Union, Luxemburg, pp 21-23

van Oers L, de Koning A, Guinée JB, Huppes G (2002) Abiotic resource depletion in LCA: improving characterisation factors for abiotic resource depletion as recommended in the new Dutch LCA handbook. Road and Hydraulic Engineering Institute, Ministry of Transport and Water, Amsterdam

West J (2011) Decreasing metal ore grades: are they really being driven by the depletion of high-grade deposits? J Ind Ecol 15(2):165-168

Yaksic A, Tilton J (2009) Using the cumulative availability curves to assess the threat of mineral depletion: the case of lithium. Resour Policy 24:185-194 